\title{
Emissions of BVOC from lodgepole pine in response to mountain pine beetle attack in high and low mortality forest stands
}

\author{
T. R. Duhl ${ }^{1}$, D. Gochis ${ }^{2}$, A. Guenther ${ }^{1}$, S. Ferrenberg ${ }^{3}$, and E. Pendall ${ }^{4}$ \\ ${ }^{1}$ Atmospheric Chemistry Division, National Center for Atmospheric Research, Boulder, CO 80307, USA \\ ${ }^{2}$ Research Applications Laboratory, National Center for Atmospheric Research, Boulder, CO 80307, USA \\ ${ }^{3}$ Department of Ecology \& Evolutionary Biology, University of Colorado, Boulder, CO 80309, USA \\ ${ }^{4}$ Program in Ecology, University of Wyoming, Laramie, WY 82071, USA
}

Correspondence to: T. R. Duhl (duhl@ucar.edu)

Received: 12 May 2012 - Published in Biogeosciences Discuss.: 24 July 2012

Revised: 12 December 2012 - Accepted: 19 December 2012 - Published: 25 January 2013

\begin{abstract}
In this screening study, biogenic volatile organic compound (BVOC) emissions from intact branches of lodgepole pine (Pinus contorta) trees were measured from trees at two forested sites that have been impacted differently by the mountain pine beetle (MPB), with one having higher mortality and the other with lower mortality. Differences in the amounts and chemical diversity of BVOC between the two sites and from apparently healthy trees versus trees in different stages of MPB attack are presented, as well as (for one site) observed seasonal variability in emissions. A brief comparison is made of geological and climatic characteristics as well as prior disturbances (both natural and man-made) at each site. Trees sampled at the site experiencing high MPB-related tree mortality had lower chemodiversity in terms of monoterpene (MT) emission profiles, while profiles were more diverse at the lower-mortality site. Also at the higher-mortality site, MPB-infested trees in various stages of decline had lower emissions of sesquiterpenes (SQTs) compared to healthy trees, while at the site with lower mortality, MPB-survivors had significantly higher SQT emissions during part of the growing season when compared to both uninfested and newly infested trees. SQT profiles differed between the two sites and, like monoterpene and oxygenated VOC profiles, varied through the season. For the low-mortality site in which repeated measurements were made over the course of the early summer-late fall, higher chemical diversity was observed in early- compared to late-season measurements for all compound classes investigated (MT, oxygenated VOC, and SQT), with the amount of change appearing to correlate to the MPB status of the
\end{abstract}

trees studied. Emissions of 2-methyl-3-buten-2-ol (MBO) had a distinct seasonal signal but were not much different between healthy or infested trees, except in trees with dead needles, from which emissions of this compound were negligible, and in late-season MPB survivors, in which they were higher than in newly infested or uninfested trees. Emissions of SQT were significantly higher in the MPB survivors during both mid- and late-season sampling at the low-mortality site. The changes in emissions could have implications for regional air quality and climate through changes in ozone and aerosol distributions, although this study was designed as a preliminary screening effort and not enough individuals were sampled for all of the observed differences to be statistically demonstrated. Despite this, the compelling differences in emissions observed between the sites and individual trees with differing MPB-infestation statuses and the potential impacts these have on regional atmospheric chemistry argue for further research in this topic.

\section{Introduction}

The vast pine forests of western North America have recently been the stage for an unprecedented epidemic of mountain pine beetle (MPB; Dendroctonus ponderosae) infestation, with the latitudinal extent of the attack spanning from Canada to Mexico and extending westward from Nebraska to the Pacific coast. The reasons behind the magnitude and sweeping extent of the current epidemic are not fully known, although several factors may be at work. Years of drought

Published by Copernicus Publications on behalf of the European Geosciences Union. 
in many parts of the afflicted areas have made trees less fit to ward off MPB attack (Allen et al., 2010; Breshears et al., 2005). Warmer temperatures experienced in recent decades over much of the region have resulted in fewer beetle kill events, which usually occur during early and late freezes, as it is during these times when the insects are in their most vulnerable developmental stages (Raffa et al., 2008; Robbins, 2010). Milder temperatures have also created longer growing seasons, which may have allowed more than one generation of MPB to propagate each year (Mitton and Ferrenberg, 2012). Mature forests are also known to be more vulnerable to MPB, while varying forest management strategies (clearcutting, thinning, fire suppression, etc.) may also heighten vulnerabilities (e.g., Pendall et al., 2010; USDA Forest Service, 2011).

There are numerous potential ramifications associated with the large-scale die-off of forests in western North America, including forests becoming a source, rather than a sink for carbon (Kurz et al., 2008), loss of species habitat, changes in local land-atmosphere exchanges (Wiedinmyer et al., 2012), increased fire susceptibility from dead and dying timber stands, changes in snowpack and water quality, threats to critical water supplies, etc. (Clow et al., 2011; Pugh and Small, 2012). Edburg et al. (2012) have hypothesized a chronological sequence of impacts as a cascade of ecological changes of which biogenic emissions may be an important outcome.

Terrestrial vegetation, particularly forests, is a major source of reactive biogenic volatile organic compounds (BVOCs) to the atmosphere. These emissions influence atmospheric oxidant chemistry and contribute to secondary aerosol formation, thus playing a role in both climate and air quality. Insect herbivory triggers changes in both the quantities and compositions of BVOC emissions from many types of vegetation. MPBs identify and select suitable host trees via olfactory cues from trees, including some particular BVOC emissions (Seybold et al., 2006). Although MPB attacks several pine species, lodgepole pine (Pinus contorta) is its main target (Powell and Raffa, 2011). Endophytic pine bark beetles such as MPB are thought to fly mainly within the stem height of potential host trees (Safranyik et al., 2010; Seybold et al., 2006), and thus many ecologically driven studies have focused on emissions of volatiles (mainly monoterpenes) associated with boles in tree trunks (e.g., Billings et al., 1976; Gara et al., 1993; Pettersson, 2001). A less understood consequence of infestation is its effects on branch-level chemical emissions from afflicted trees, which emit various compound classes in addition to monoterpenes (such as 2methyl-3-buten-2-ol, oxygenated compounds and sesquiterpenes), and could have substantial implications for regional atmospheric chemistry.

The objectives of the current study were two-fold. First, branch-level BVOC emissions were screened in two lodgepole pine forest locations that have been impacted differently by the MPB: one with high lodgepole mortality (up

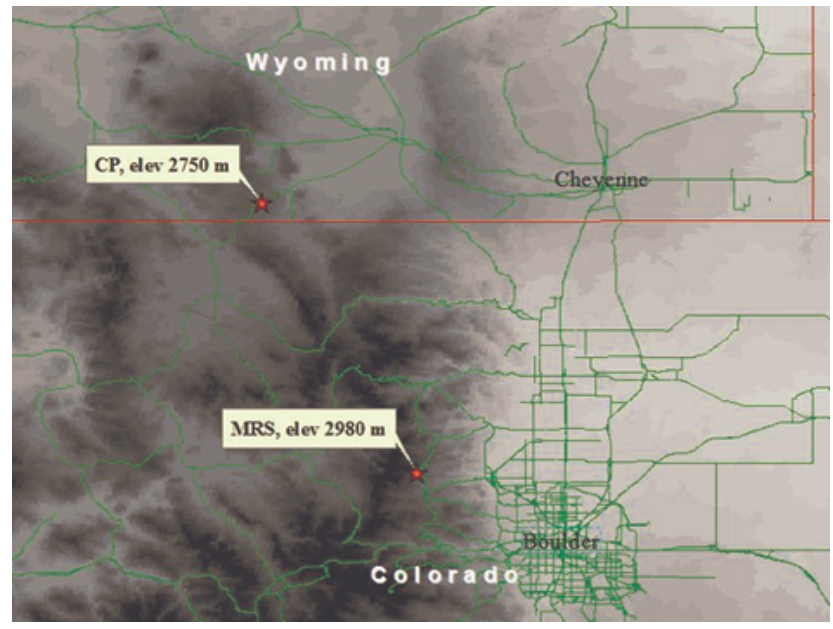

Fig. 1. Location of the Chimney Park and Mountain Research Station sampling sites

to $70 \%$, which is typical over much of the western Rocky Mountains) and another in which die-off from MPB has been much lower $(<5 \%)$. The second objective was to characterize the seasonal variability among healthy, uninfested trees, and from trees in varying stages of MPB attack at one of the sites. The BVOC emission measurements described in this paper were performed at two lodgepole pine-dominated forest sites: Chimney Park (CP), Wyoming and the University of Colorado Mountain Research Station (MRS). The study was performed as a preliminary screening effort to determine whether site-specific and/or infestation status-related differences in branch-level BVOC emissions were compelling enough to affect fluxes of these compounds to the atmosphere and thus warrant further inquiry and measurements at the sites.

\section{Methods}

Different classes of trees were sampled depending on the site; descriptions and sampling codes used for each site are presented in Table 1. At CP, three classes of trees were sampled: healthy, uninfested trees (referred to hereafter as "Live Green" or "LG" trees); trees infested with the MPB but still containing predominantly live green foliage ("Beetle Green" or "BG" trees); and late-stage infested trees whose needles had all turned red but had not yet fallen ("Beetle Red" or "BR" trees). At MRS, where there were no "BR" lodgepole trees, we sampled BG trees (referred to as "old_beetle" or "OB" trees), apparently healthy uninfested trees before and after being baited with lures and subsequently attacked by MPB ("Before Baiting" or "BB", and "After Baiting" or "AB", respectively), and apparently healthy uninfested trees not baited with MPB lures (referred to as "control" or "CT" trees). At both sites, the health and MPB status of trees selected for sampling were determined visually and confirmed 
Table 1. Descriptions of trees sampled at CP and MRS, site characteristics, summary of site disturbance and management histories, and hydrological/climatic characteristics of $\mathrm{CP}$ and MRS sampling sites. precip. $=$ precipitation; avg. $=$ average; $T=$ temperature, P.T.C. $=$ pitch tube count.

\begin{tabular}{|c|c|c|c|}
\hline Site & $\begin{array}{l}\text { Tree classes sampled, } \\
\text { tree codes for each } \\
\text { tree sampled in class }\end{array}$ & $\begin{array}{l}\text { Site characteristics, management and disturbance histories, } \\
\text { avg. P.T.C. for infested trees }\left(\mathrm{m}^{-2}\right) \text { and soil families }\end{array}$ & $\begin{array}{l}\text { Site hydrological and climatic } \\
\text { characteristics }\end{array}$ \\
\hline $\mathrm{CP}$ & $\begin{array}{l}\text { Un-infested apparently } \\
\text { healthy, LG1, LG2, LG3 }\end{array}$ & $\begin{array}{l}\text { CP tree stands vary in density and basal area (Table 2), } \\
\text { reflecting differences in natural regeneration since the last }\end{array}$ & $\begin{array}{l}\text { Avg. annual precip.: } 435 \mathrm{~mm} \\
(\geq 2 / 3 \text { falls as snow). In the } 5 \text { - and }\end{array}$ \\
\hline $\mathrm{CP}$ & $\begin{array}{l}\text { Infested } 1-3 \text { yr prior to } \\
\text { sampling, green needles, } \\
\text { BG1, BG2, BG3 }\end{array}$ & $\begin{array}{l}\text { major disturbances that occurred in the area (early 20th } \\
\text { century), including logging, stand-replacing fire, and (more } \\
\text { recently) management activities (thinning and harvest). Since }\end{array}$ & $\begin{array}{l}10 \text {-yr periods prior to the } \\
\text { sampling year }(2010), \mathrm{CP} \\
\text { received an avg. of } 106 \% \text { and }\end{array}$ \\
\hline $\mathrm{CP}$ & $\begin{array}{l}\text { Infested } 1-3 \text { yr prior to } \\
\text { sampling and in decline } \\
\text { (red needles), BR1, BR2 }\end{array}$ & $\begin{array}{l}\sim 2007, \text { CP has seen rather intense infestation by the MPB, } \\
\text { resulting in as much as } 70 \% \text { tree mortality in some of the } \\
\text { stands. Avg. P.T.C.: } 87 \text { (BG) } 60 \text {, (BR). Soils are mainly Typic } \\
\text { Cryocrepts-Typic Cryoboralfs (Knight, 1991). }\end{array}$ & $\begin{array}{l}110 \% \text { of normal precip., with } \\
\text { punctuated deficits in annual } \\
\text { precip. (e.g., } 81 \% \text { of avg. in } 2002 \text { ). } \\
\text { Avg. annual temp: } 1^{\circ} \mathrm{C} \text {. }\end{array}$ \\
\hline MRS & $\begin{array}{l}\text { Un-infested trees used as } \\
\text { controls, CT1, CT2 }\end{array}$ & $\begin{array}{l}\text { The trees growing in and around MRS have not been } \\
\text { extensively managed since widespread cutting that continued }\end{array}$ & $\begin{array}{l}\text { Avg. annual precip.: } 730 \mathrm{~mm} \\
(\geq 2 / 3 \text { falls as snow). In the } 5 \text { - and }\end{array}$ \\
\hline MRS & $\begin{array}{l}\text { Apparently un-infested } \\
\text { trees sampled before MPB } \\
\text { baiting, BB1, BB2 }\end{array}$ & $\begin{array}{l}\text { throughout the } 1800 \text { s until } \sim 1910 \text {. Large-scale wildfires are } \\
\text { rare in lodgepole forests near the MRS over the past } 300-400 \mathrm{yr} \\
\text { (Sibold et al., 2006). Episodic MPB outbreaks have been }\end{array}$ & $\begin{array}{l}10 \text {-yr periods prior to the } \\
\text { sampling year (2011), MRS } \\
\text { received an average of } 99 \% \text { of }\end{array}$ \\
\hline MRS & $\begin{array}{l}\text { BB trees (from above) } \\
\text { sampled after MPB baiting } \\
\text { and subsequent infestation, } \\
\mathrm{AB} 1, \mathrm{AB} 2\end{array}$ & $\begin{array}{l}\text { recorded for nearby forests in the } 1930 \text { s and } 1970 \text { s (Sibold et } \\
\text { al., 2007), with the most recent infestations at the MRS } \\
\text { beginning in } 2007 \text {. Lodgepole mortality among naturally } \\
\text { infested trees is }<5 \% \text {, but much higher }(>40 \% \text { ) in limber pines. }\end{array}$ & $\begin{array}{l}\text { normal precipitation (during } \\
\text { both periods), with punctuated } \\
\text { deficits in annual precipitation } \\
\text { (e.g., } 78 \% \text { of avg. in 2002). }\end{array}$ \\
\hline MRS & $\begin{array}{l}\text { Trees infested } 1-3 \mathrm{yr} \\
\text { prior to sampling with no } \\
\text { sign of decline, OB1, OB2 }\end{array}$ & $\begin{array}{l}\text { P.T.C.: } 51.8 \text { (baited), } 97.2 \text { (naturally infested). Soils are mainly } \\
\text { typic cryocrepts with typic cryoboralfs also present (Veblen } \\
\text { and Donnegan, 2005; Birkeland et al., 2003). }\end{array}$ & Avg. annual temp: $1.6^{\circ} \mathrm{C}$. \\
\hline
\end{tabular}

with the help of coauthors with expert site-specific knowledge of the local MPB dynamics and history. MPB infestation was determined by looking for visual indications of infestation, including bore-holes, boring dust on bark crevices or at the base of trees, missing patches of bark, red needles, and/or any other visually apparent signs of infestation or distress. Mature trees with a minimum diameter at breast height (DBH) of $15 \mathrm{~cm}$ were selected for sampling. The sampling design was as follows: each day, three branch enclosures (described later) were sampled, one from each of the sample classes, with three individuals from each group selected for sampling.

\subsection{Chimney Park site description and sampling design}

Chimney Park $\left(\sim 41^{\circ} 04^{\prime} \mathrm{N}, 106^{\circ} 07^{\prime} \mathrm{W}\right.$, elev. $\sim 2750 \mathrm{~m}$ a.s.1.), located in southern Wyoming, USA (Fig. 1) in the Medicine Bow National Forest, is a forested landscape dominated by lodgepole pine (Pinus contorta) and has a long history of experimental research dating back to the 1970s. At the time of the sampling visit, there were six stands within $\mathrm{CP}$ actively being used for experimental purposes. Trees growing in or near four of these stands were selected for sampling for this study (Table 2).

Measurements at CP were made from 15-17 September 2010. The enclosures for each day were generally installed on three trees growing as near as possible to each other (Table 2), although it was not always feasible to find a tree from each sampling category growing in the same stand. Due to pump failure on day three, no BR enclosure was installed.

\subsection{Mountain Research Station site description and sampling design}

The University of Colorado's Mountain Research Station $\left(\sim 40^{\circ} 02^{\prime} \mathrm{N}, 105^{\circ} 32^{\prime} \mathrm{W}\right.$, elev. $\left.\sim 2980 \mathrm{~m}\right)$ is located in the Roosevelt National Forest in north-central Colorado $(35 \mathrm{~km}$ west of Boulder; Fig. 1) and has been used as an experimental and research forest since at least the 1920s. The MRS site description and extensive climate data are available from the NSF-supported Niwot Ridge Long-Term Ecological Research project and the University of Colorado Mountain Research Station (http://culter.colorado.edu/NWT/index.html). The site where BVOC sampling was conducted is dominated by both lodgepole and limber (P. flexilis) pine trees. Although MPB infestation has been observed in the MRS site, outbreaks have not been widespread and have mostly focused on the limber pines. Those lodgepole trees that have been hit appear to be surviving the beetle attacks (lodgepole mortality from MPB at MRS is $<5 \%$ ). The reasons for this resilience are not known, but may reflect water status, a resistance to the strains of blue-stain fungus carried by the beetles at the site, or other unknown factors. Some tree mortality from MPB at the MRS has occurred in a 
Table 2. Stand characteristics for trees sampled at CP (September 2010) and MRS (June-September 2011) and meteorological conditions during sampling. PAR is expressed in units of $\mu \mathrm{mol} \mathrm{s}{ }^{-1} \mathrm{~m}^{-2}$; ambient temperatures (amb. $T$ ) are expressed as ${ }^{\circ} \mathrm{C}$.

\begin{tabular}{|c|c|c|c|}
\hline Tree code(s) & $\begin{array}{l}\text { Characteristics of stand containing } \\
\text { sampled trees }\end{array}$ & $\begin{array}{l}\text { Avg. distance }(\mathrm{m}) \text { between } \\
\text { trees sampled at site }\end{array}$ & $\begin{array}{l}\text { Sampling dates and meteorological } \\
\text { conditions during sampling }\end{array}$ \\
\hline $\begin{array}{l}\text { (CP) LG1 } \\
\text { (CP) BG1 }\end{array}$ & 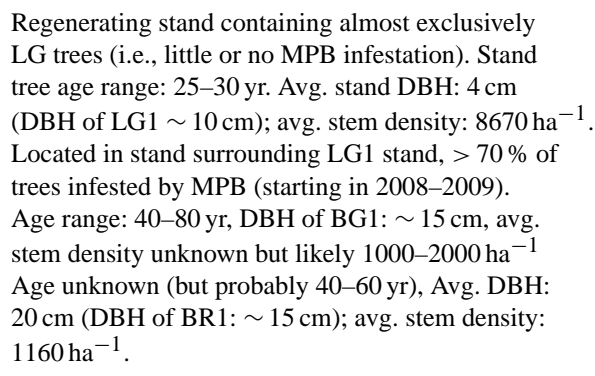 & $\begin{array}{l}35 \mathrm{~m} \text { from } \mathrm{BG} 1,140 \mathrm{~m} \\
\text { from } \mathrm{BR} 1, \sim 150 \mathrm{~m} \text { from } \\
\mathrm{LG} 2, \mathrm{BG} 2, \text { and } \mathrm{BR} 2 ; 335 \mathrm{~m} \\
\text { from } \mathrm{LG} 3,445 \mathrm{~m} \text { from } \mathrm{BG} 3 . \\
155 \mathrm{~m} \text { from } \mathrm{BR} 1, \sim 185 \mathrm{~m} \\
\text { from } \mathrm{LG} 2, \mathrm{BG} 2, \text { and } \mathrm{BR} 2,370 \mathrm{~m} \\
\text { from } \mathrm{LG} 3,475 \mathrm{~m} \\
\text { from } \mathrm{BG} 3 \text {. } \\
\sim 185 \mathrm{~m} \text { from } \mathrm{LG} 2, \mathrm{BG} 2, \\
\text { and } \mathrm{BR} 2 ; 475 \mathrm{~m} \text { from } \mathrm{BG} 3 .\end{array}$ & $\begin{array}{l}15 \text { Sep } \\
\text { PAR: } 140-1650 \text {, corresponding with } \\
\text { changing full sun/partial cloud } \\
\text { conditions, amb. } T: 15-26\end{array}$ \\
\hline (CP) LG2, BG2, BR2 & $\begin{array}{l}\text { Managed (thinned) stand. Infested by MPB in } \\
\text { 2009., avg. DBH: } 14 \mathrm{~cm} \text {; avg. stem density: } \\
2250 \mathrm{ha}^{-1}\end{array}$ & $\begin{array}{l}\text { avg. distance between LG2, } \\
\text { BG2, and BR2: } 23 \mathrm{~m}\end{array}$ & $\begin{array}{c}\text { 16 Sep } \\
\text { PAR: 46-770, partly cloudy } \\
\text { to mostly sunny, amb. } T: 17-26\end{array}$ \\
\hline (CP) BG3 & $\begin{array}{l}\text { Most heavily infested stand sampled (site of } \\
\text { earliest outbreak at CP starting in } \sim 2007) \text {. } \\
\text { Mostly sparsely distributed BR trees. Age } \geq 80 \mathrm{yr} \text {, } \\
\text { avg. DBH: } 25 \mathrm{~cm} \text {, avg. stem density: } 730 \mathrm{ha}^{-1} \text {. } \\
\text { Age unknown (but probably } 50-70 \mathrm{yr} \text { ), DBH } \\
\text { of LG3: } \sim 18 \mathrm{~cm} \text {; stem density unknown. }\end{array}$ & $\begin{array}{l}\sim 300 \mathrm{~m} \text { from } \mathrm{LG} 2, \mathrm{BG} 2, \\
\text { and BR2 }\end{array}$ & $\begin{array}{l}17 \text { Sep } \\
\text { PAR: } 90-1070 \text {, partly cloudy to } \\
\text { mostly sunny, amb. } T: 19-26\end{array}$ \\
\hline (MRS) all trees & $\begin{array}{l}\text { Avg. DBH }=23 \mathrm{~cm} \text {, avg. stem density }=1500 \mathrm{ha}^{-1} \text {. } \\
\text { Age distribution is roughly normal with a narrow } \\
\text { age span of } \sim 130 \mathrm{yr} \text { (Knowles and Grant, 1983). } \\
\text { Infection by dwarf mistletoe } \\
\text { (Arceuthobium americanum) is common among } \\
\text { MRS lodgepole pines, but does not appear to } \\
\text { significantly affect tree mortality following MPB } \\
\text { attack (Ferrenberg, unpublished data). }\end{array}$ & $\begin{array}{l}\text { all MRS trees were growing } \\
\text { within } 40 \mathrm{~m} \text { of each other }\end{array}$ & $\begin{array}{l}\text { 30 Jun-1 Jul: PAR, 40-2110; } \\
\text { amb. } T, 14-25 \text {, mostly cloudy } \\
\text { to mostly sunny. } \\
\text { 7-8 Aug: PAR, } 70-2250 \text {; amb. } T \text {, } \\
\text { 20-26, full sun to mostly sunny. } \\
\text { 17-18 Sep: PAR, } 135-1600 \text {, amb. } T \text {, } \\
\text { 9-15 }{ }^{\circ} \text { C, mostly cloudy to } \\
\text { mostly sunny. }\end{array}$ \\
\hline
\end{tabular}

small-scale experimental manipulation study that uses commercially available pheromones to attract MPB to specified host trees (Mitton and Ferrenberg, 2012). It is these experimentally baited trees (along with several unbaited trees) that were sampled at MRS.

The sampling approach taken at MRS was different than that at CP. We had the unique opportunity to sample trees before and after they were infested with MPB, thanks to the tree-baiting experiment fully described by Mitton and Ferrenberg (2012). The objective of the MPB baiting experiment was to ensure MPB attacks for documenting MPB flight seasons and generation times between limber and lodgepole pine hosts. Pine trees used in the experiment were selected because they were mature canopy or sub-canopy trees $(>20 \mathrm{~cm}$ $\mathrm{DBH}$ ) and had no evidence of prior MPB attacks. The timing of baiting with MPB aggregation pheromone coincided with the 2011 peak flight of MPB at the MRS (Ferrenberg and Mitton, unpublished data).

We planned three 2-day sampling visits to the MRS site from summer to early fall of 2011: 30 June-1 July, 7-8 August and 17-18 September. The first sampling visit was chosen to be at a time before MPBs were observed to be flying in the area but after temperatures had warmed up enough to allow the trees to become active in terms of BVOC emis- sions (generally, this occurs in late May-early June; however, the summer of 2011 was rather cold and rainy, so the pre-baiting measurements were conducted 30 June-1 July). The second visit (7-8 August) was timed to occur just after baiting and close to the week of peak beetle flight in the area, and the third (and final) visit to the site was performed on 17-18 September. This time period was chosen to be close to the same time of year that sampling at $\mathrm{CP}$ was performed (for comparison purposes).

\subsection{Sampling methods}

Branch enclosures at both sites consisted of custom-made Tedlar bags, each of which contained a $1 / 8^{\prime \prime}$ PTFE/stainless steel sampling port located on the edge of the bag furthest from the base of the branch. The bags were placed carefully over the selected branches, ensuring to the best extent possible that needle surfaces were not in contact with the enclosure walls. The enclosures were secured over the branches using $\sim 0.2 \mathrm{~cm}$ diameter elastic cords. Enclosure volumes ranged from $\sim 7-10 \mathrm{~L}$, depending on the size of the enclosed branch. Purge air was delivered into the enclosure through a $1 / 4^{\prime \prime}$ PTFE tube (fed into the bag through the bag opening along the branch), connected to a micro-diaphragm pump 
(KNF, type UNMP830KNDC, Neuberger Inc., Trenton, NJ, USA) powered by a rechargeable $12 \mathrm{~V}, 9$ Ah sealed battery (WKA12-9F2, Werker, China). The purge air supply pump and battery were placed inside a plastic bin to protect against water intrusion in the case of inclement weather. The pump storage bin was located on the ground at the base of the tree being sampled, except in the case of one CP tree, on which the selected sampling branch (the lowest accessible branch on the tree) was high enough above ground $(\sim 3.7 \mathrm{~m})$ that the pump enclosure was placed on a ladder. This was done to minimize the length of the enclosure purge air supply line, as it was determined that the length of this line inversely affected the air flow delivery rate of the pump.

The inlet to the pump was fitted with an activated charcoalfilled glass tube (ORBO-32, Supelco, Bellefonte, PA, USA) to scrub the inlet air of ambient VOC and oxidants. One inlet sample was collected at some point in between sample collection at each enclosure, to ensure that ambient VOCs were not influencing the sampled enclosure air. For each quantified and speciated BVOC found in enclosure samples, the reported emission rate of the compound was reduced by the inlet concentration (if detected) from the enclosure inlet sample. For most enclosures and compounds, inlet concentrations were much lower than $1 \%$ of concentrations observed exiting the enclosures. The enclosures were installed on the branches $\sim 16-18 \mathrm{~h}$ prior to the start of sampling, in order to allow any installation-induced emission bursts to subside and to give the enclosure time to equilibrate prior to sampling. As samples were generally collected starting near 12:00 local time, enclosures were installed during the late afternoon/evening of the previous day. Prior to sampling each day, the charcoal inlet scrubber was removed and replaced, and the battery powering the enclosure purge pump was changed.

Temperature inside of the enclosure was measured using either a thermocouple (type K, OMEGA Engineering, Inc., Stamford, CT, USA) or a HOBO temperature sensor (TM6HE, Onset, Cape Cod, MA, USA). The temperature sensors were fed into the enclosure bag along the base of the branch and shielded from direct solar radiation. Photosynthetically active radiation (PAR) outside of (but next to) the branch enclosure was measured using Quantum sensors (using either LI-190, LI-COR Environmental, Lincoln, NE, USA or Apogee SQ-110, Apogee Instruments, Logan, UT, USA). The PAR sensors were mounted onto a leveled tripod at the same height as the branch being measured. Temperature and light data were logged using HOBO data loggers (model No. U12-014, H08-004-02, or H08-006-04, Onset, Cape Cod, MA, USA). The HOBO data loggers were evaluated indoors prior to deployment and were compared with real-time thermocouple temperature readings; temperature responses were within $0.5^{\circ} \mathrm{C}$ between each of the sensors/loggers.

Branch enclosure outlet and inlet air samples were collected onto stainless steel cartridges filled with adsorbent. The two-stage cartridges were either custom-filled in-house with a mixture of $\sim 150 \mathrm{mg}$ of Tenax TA $(60 / 80$ mesh, Buchem BV, Apeldoorn, the Netherlands) and $\sim 170 \mathrm{mg}$ Carbotrap (20/40 mesh, Sigma-Aldrich Co. LLC, St. Louis, MO, USA) or purchased pre-filled with $\sim 350 \mathrm{mg}$ of Tenax GR (35/60 mesh) and Carbograph 5TD (40/60 mesh; Markes International, Llantrisant, RCT, UK). Samples were collected using custom-made, mass-flow-controlled pumps designed and built in-house. Sampling rates varied from 150$200 \mathrm{~mL} \mathrm{~min}^{-1}$, and samples were collected for $30 \mathrm{~min}$.

After sampling was completed, the sampled branches were harvested, dried in a $\sim 60^{\circ} \mathrm{C}$ oven for $48 \mathrm{~h}$, and weighed (both for needle and non-needle biomass). At MRS, repeated measurements were made on dedicated branches from the selected trees during each visit, rather than on different branches. Since emission rates are generally expressed as a function of dry biomass weight, several pictures of each branch were taken at the beginning of sampling in late May to confirm whether any branches had lost needles or twigs over the course of the campaign. None of the branches experienced detectable loss of needles or twigs during the campaign, but, by the third sampling period, many of the branches had dead or dying needles, and when enclosures were installed during this last visit, care was taken to preserve these needles on the branches (or at least keep them inside of the enclosure bags). During the second and third sampling periods, the number of yellowing and/or completely red needles was recorded for each branch. Final emission rate calculations were made after harvesting and drying the branches (after the final round of sampling) and calculating the expected live biomass dry weight for each of the sample periods.

It is well-known that pine trees shed needles each year and re-grow new needles; this behavior can affect the calculated emission rates for the trees sampled at MRS during June-July and during August, since the needles sampled from trees during these measurement periods were not harvested and weighed until after the collection of the September samples. Needle longevity among lodgepole pines growing at elevations comparable to that of the MRS site was shown to vary between approximately 10-13 yr (corresponding to an average annual loss rate of $\sim 8-10 \%$ per year), while new foliar growth among lodgepole pine (expressed as annual incremental change in foliated shoot length) was found to be $\sim 6-7 \%$ (Schoettle, 1990). The MRS study took place over a period of $\sim 11$ weeks, while the estimates of new foliar growth provided by Schoettle (1990) are based on annual changes (although most new foliar growth would be expected to occur at high-altitude sites such as MRS between $\sim$ May-August). Given these observations, we estimate that overall biomass change during the course of the MRS study was likely $<5 \%$. Nonetheless, these potential small changes in biomass between the June-July and August measurement periods should be considered as a caveat when interpreting the emission rates obtained for the June-July and August MRS samples. Readers interested in more information about 
branch enclosure-based sampling are directed to Ortega and Helmig (2008).

\subsection{Analytical methods}

Air sampling cartridges were thermally desorbed using an Ultra autosampler (Series 2, model ULTRA TD, Markes International, Llantrisant, RCT, UK), and analytes were then cryo-focused onto a Unity thermal desorber (Markes International, Llantrisant, RCT, UK) operated in splitless mode. The samples were subsequently injected into a gas chromatograph (GC; model 7890A, Agilent Technologies, Inc., Santa Clara, CA, USA). Flow path temperatures within the UltraUnity were maintained at $175^{\circ} \mathrm{C}$. The $\mathrm{GC}$ was equipped with a flame ionization detector (FID) and a mass-selective detector (MSD; 5975C inert MSD, Agilent Technologies, Inc., Santa Clara, CA, USA), and had an HP-5MS column $(30 \mathrm{~m} \times 0.25 \mathrm{~mm}, 0.25 \mu \mathrm{m}$, Agilent Technologies, Inc., Santa Clara, CA, USA), using nitrogen as a carrier gas.

The MSD was run simultaneously in both SIM and SCAN modes, allowing detection of both routinely observed compounds as well as those less frequently found. Compounds detected in samples taken during the 2010 Chimney Park campaign were quantified using the FID along with an external gas-phase standard containing $71 \mathrm{ppbV}$ isoprene and $48 \mathrm{ppbV}$ camphene. In cases where analytes could not be quantified using the FID signal, the relative SIMor SCAN-mode MSD response of the target ion for the compound was quantified relative to the response for the same (or similar) ion quantified in the external standard. The GC oven heating program used in the analysis of the Chimney Park samples was as follows: start temperature, $35^{\circ} \mathrm{C}$; hold time, $1 \mathrm{~min}$; Ramp $1,6^{\circ} \mathrm{C} \mathrm{min}^{-1} \rightarrow 80^{\circ} \mathrm{C}$ (no hold time); Ramp $2,3^{\circ} \mathrm{C} \min ^{-1} \rightarrow 155^{\circ} \mathrm{C}$ (no hold time); Ramp 3, $10^{\circ} \mathrm{C} \min ^{-1} \rightarrow 190{ }^{\circ} \mathrm{C}$ (no hold time); Ramp 4, $25^{\circ} \mathrm{C} \mathrm{min}{ }^{-1} \rightarrow 260^{\circ} \mathrm{C}$; final hold time $5.2 \mathrm{~min}$ (total run time, $45 \mathrm{~min})$.

For samples analyzed during the 2011 MRS Ridge campaign, quantifications were performed using the FID and a gas-phase external standard containing $165 \mathrm{ppbV}$ isoprene and $71 \mathrm{ppbV}$ camphene. Additionally, for samples collected in 2011, an internal standard consisting of $\sim 1 \mathrm{ppm} \mathrm{e-}$ decahydronaphthalene was added to each sample analyzed. The GC oven temperature ramping program used for the analysis of the MRS samples was as follows: start temperature, $-30^{\circ} \mathrm{C}$; hold time, $1 \mathrm{~min}$; $\operatorname{Ramp} 1,20^{\circ} \mathrm{C} \mathrm{min}{ }^{-1} \rightarrow 0{ }^{\circ} \mathrm{C}$ (no hold time); Ramp $2,6^{\circ} \mathrm{C} \mathrm{min}^{-1} \rightarrow 80^{\circ} \mathrm{C}$ (no hold time), Ramp 3, $3{ }^{\circ} \mathrm{C} \mathrm{min}^{-1} \rightarrow 190^{\circ} \mathrm{C}$ (no hold time), Ramp 4, $30^{\circ} \mathrm{C} \mathrm{min}$ min $^{-1} \rightarrow 260^{\circ} \mathrm{C}$; final hold time 5.9 min (total run time, $60.7 \mathrm{~min}$ ).

Blank samples were also analyzed for each day of the sampling campaign; both opened and unopened blanks were analyzed to determine potential contributions to detected analytes from background concentrations or sample handling and storage activities. For any compounds detected in the samples that were also found in blanks, the maximum amount of analyte detected in the blank was subtracted from the enclosure samples for that day. For most compounds investigated, an analytical precision of $\pm 3 \%$ was estimated based on repeated analyses of gas-phase standards, while accuracies of quantitative emission results reported using SIM ion quantitation are estimated at $\pm 15 \%$. There is an uncertainty of $\sim 30 \%$ associated with reported OVOC ERs (emission rates) and speciation profiles.

\subsection{Emission rate calculation and statistical methods}

ERs and ratio analyses (i.e., the contribution to each compound class by individual compounds) are presented for three or four groups of compounds/compound classes (depending on the site): 2-methyl-3-buten-2-ol (MBO), monoterpenes (MTs), sesquiterpenes (SQTs), and oxygenated volatile organic compounds (OVOCs, results available for MRS site only). For all compounds, we report ranges of observed ERs and, if appropriate, results from linear regressions. For MT and SQT, basal emission rates (BERs, i.e., emissions normalized to standard conditions of $30^{\circ} \mathrm{C}$ ) and corresponding standard deviations are reported, though it should be noted that there was substantial variability in enclosure temperatures and emissions observed during the study, and the expected exponential relationships between MT and/or SQT emissions and temperature were frequently not observed. BERs were calculated using Eq. (5) from Guenther et al. (1993): $\mathrm{BER}=\mathrm{ER}_{T} /(\exp [\beta(T-\mathrm{Ts})])$, where $\mathrm{ER}_{T}=\mathrm{ER}$ observed at temperature $T, \mathrm{Ts}=30^{\circ} \mathrm{C}$, and $\beta=0.1$ for MT (Guenther et al., 1993) and 0.15 for SQT (Duhl et al., 2008). For MBO and OVOC, average ERs and associated standard deviations are reported instead of BERs. All ERs and BERs reported in the text are in units of $\mu \mathrm{g} \mathrm{Cg}_{\mathrm{dw}}^{-1} \mathrm{~h}^{-1}$.

Two-sample t-tests were used to verify whether observed differences in total MT BER and SQT BER were significant between individual trees and/or sampling classes (depending on the site and number of samples/individuals screened). Prior to running the t-tests, F-tests were performed on each variable tested. When the results of the F-tests indicated that variance was not significantly different (for $\alpha=0.01$ ), variances were pooled for the t-test calculations. Statistical tests were not performed for MBO or other OVOC emissions due to the lack of well-constrained techniques to normalize these emissions to account for light and temperature effects.

$\mathrm{K}$-means cluster analysis of September MT profiles was applied to the live trees at both CP (ie., LG and BG trees, $n=6$, excluding the presumably dead BR trees) and MRS (all trees, $n=6$, since no dead trees were sampled at MRS) to look for significant differences in MT profiles, which would indicate the presence of different chemotypes at the sites. Cluster solutions for each site were tried for the three or five most dominant MT (since these contributed most of the observed variability) and for all MT detected (excluding MT that comprised $<0.1 \%$ of average MT composition) after 
Bäck et al. (2012). The sum of squared error (SSE) for every possible selected cluster solution was tested against the SSE using 250 randomized versions of the original input data. The SSE of strong cluster solutions would be expected to decrease more quickly than the randomized SSE solutions as the number of clusters increases. Principal component analyses (PCAs) were also performed for the selected cluster solutions and the clusters plotted based on the PCA results for the first two principal components. Strong clusters would be expected to have good structure and little or no overlap in the PCA plot space.

\section{Results}

\subsection{Chimney Park, WY, results}

During the course of the three-day sampling campaign, a total of 29 enclosure samples and 7 inlet samples were collected. However, it was discovered that 9 of the cartridges used during the $\mathrm{CP}$ sampling campaign had damaged adsorbent materials and the results from these cartridges were therefore excluded from analysis. Despite this loss of data, several qualitative differences in absolute emission rates emerged between the various studied groups for two of the compound classes observed (MBO and SQT).

The BR trees emitted negligible amounts of MBO (Table 3), which is predictable given the fact that these needles appeared to be dead and MBO is known to be synthesized de novo, largely as a function of photosynthesis (e.g., Gray et al., 2003). There were no obvious class-related differences in MBO or MT emissions among the BG and LG trees (Table 6). BR1, BG3, and LG3 had the highest average MT BERs (4.15, 2.13, 1.36, respectively), while the other five trees had average BERs ranging from 0.35-0.54. The high emissions observed in BR1 could reflect the fact that, as the needles (and/or twig biomass) on this branch were dead, emissions could have been caused by simple evaporation of stored MT from pools in the tissues of this branch, or release of MT caused by needle/twig rupture during enclosure installation. The BG and BR trees had lower SQT ERs and BERs than the LG trees, even those LG branches that were subjected to comparable (or even lower) branch enclosure temperatures to their BG or BR counterparts (Fig. 2, Table 3). The LG trees emitted a significantly higher fraction of SQT than the BG trees (Table 6) and had significantly higher SQT BERs than the BG trees, although this relationship was weaker.

Although the total amounts of MT emitted from the various branches studied at $\mathrm{CP}$ varied quite a lot from individual to individual, the ratios of these compounds emitted by individual branches were remarkably similar among the LG and BG individuals sampled (Table 4), with $\beta$-pinene always comprising the largest component of emissions, followed by $\alpha$-pinene and/or $\beta$-phellandrene (and in one case,

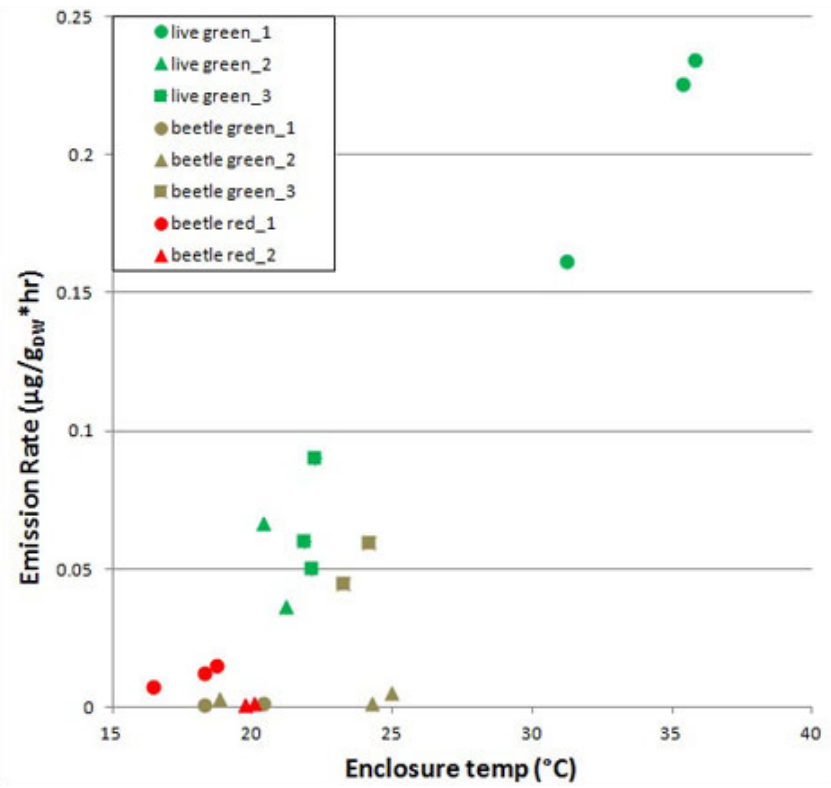

Fig. 2. SQT emissions observed at Chimney Park, WY, during midSeptember, 2010.

3-carene). The BR trees differed somewhat in the composition of their MTs, with 3-carene being dominant followed by $\beta$-pinene and/or $\beta$-phellandrene. Within-tree variation in MT composition was very low across the samples, except for the third sample collected from enclosure LG1 (which had experienced substantial heat stress, with enclosure temperatures averaging $\sim 14.6{ }^{\circ} \mathrm{C}$ above ambient temperatures over the course of the second and third sample collection periods). Only the first two samples from LG1 were included in the average shown for this tree in Table 3, since the MT ratios were very similar between these two samples. The third sample collected from LG1 (after $\sim 3.5 \mathrm{~h}$ of nearly continuous heat stress on the branch) exhibited a $\sim 10 \%$ reduction in the contribution from 3-carene (compared with the first sample collected), the appearance of $\sim 5 \% \mathrm{z}-\beta$-ocimene (which was not found in any other sample collected during the campaign and may be produced in response to stress), and small changes in the other MTs detected. Although the MT ratios for LG1 changed over the course of sampling (presumably in response to heat stress), the SQT ratios remained more or less unchanged despite the heat stress.

$\mathrm{K}$-means cluster analysis applied to the live (i.e., LG and BG) trees for three MT lumping schemes tested (i.e., using either the three or five most dominant MT or all MT detected) and for all cluster solutions evaluated (2-6 clusters) resulted in SSEs that never deviated from the SSEs of the 250 randomized versions of the original input data, indicating the presence of only one MT chemotype at CP (among live trees but irrespective of infestation). The PCA plots obtained for the various cluster solutions and lumping schemes lacked coherent structure and frequently contained overlap 
Table 3. ER and temperature $(T)$ ranges observed during the CP and MRS sampling visits; results are grouped according to compound/compound class and (when appropriate) sample class. Avg. basal ERs (BER) and corresponding standard deviations $(\sigma)$ are presented for MT and SQT; avg. ER and standard deviations are reported for MBO and OVOC.

\begin{tabular}{|c|c|c|c|c|c|c|}
\hline Site & Sampling dates & $\begin{array}{l}\text { Tree }(\mathrm{s}) \text { or } \\
\text { tree class(es) }\end{array}$ & $\begin{array}{l}\text { Cmpd. or } \\
\text { cmpd. class }\end{array}$ & $\begin{array}{l}\text { ER range } \\
\left(\mu g C g_{d w}^{-1} h^{-1}\right)\end{array}$ & $\begin{array}{r}T \text { range } \\
\left({ }^{\circ} \mathrm{C}\right) \text { of } \\
\text { enclosures }\end{array}$ & $\begin{array}{r}\text { Avg. BER }(\sigma) \text { if MT or SQT, } \\
\text { avg. ER }(\sigma) \text { if MBO } \\
\text { or OVOC }\left(\mu \mathrm{gCg}_{\mathrm{dw}}^{-1} \mathrm{hr}^{-1}\right)\end{array}$ \\
\hline $\mathrm{CP}$ & 15-17 Sep 2010 & $\mathrm{LG}, \mathrm{BG}$ & $\mathrm{MBO}$ & $0-5.38$ & $18.3-35.8$ & $1.16(1.43)$ \\
\hline $\mathrm{CP}$ & 15-17 Sep 2010 & $\mathrm{BR}$ & $\mathrm{MBO}$ & $0-0.001$ & $16.4-20.0$ & $0.0007(0.0005)$ \\
\hline $\mathrm{CP}$ & 15-17 Sep 2010 & all & MT & $0.08-1.97$ & $16.4-35.8$ & $1.16(1.47)$ \\
\hline $\mathrm{CP}$ & 15-17 Sep 2010 & LG & SQT & $0.037-0.235$ & $20.4-35.8$ & $0.165(0.071)$ \\
\hline $\mathrm{CP}$ & 15-17 Sep 2010 & BG & SQT & $0.001-0.060$ & $18.3-25.0$ & $0.045(0.061)$ \\
\hline $\mathrm{CP}$ & 15-17 Sep 2010 & BR & SQT & $0.001-0.015$ & $16.4-20.0$ & $0.038(0.038)$ \\
\hline MRS & 30 Jun-1 Jul 2011 & $\mathrm{All}^{\mathrm{a}}$ & MBO & $0.37-13.25$ & $14.2-33.0$ & $4.71(3.36)$ \\
\hline MRS & 7-8 Aug 2011 & $\mathrm{All}^{\mathrm{b}}$ & MBO & $1.29-19.09$ & $22.9-39.7$ & $8.43(5.61)^{\mathrm{d}}$ \\
\hline MRS & $17-18$ Sep 2011 & $\mathrm{AB} 1 \mathrm{~b}, \mathrm{OB} 1$ & MBO & $0.43-0.96$ & $10.5-13.4$ & $0.69(0.25)$ \\
\hline MRS & 17-18 Sep 2011 & $\mathrm{OB} 2, \mathrm{CT} 2$ & MBO & $0.37-2.25$ & $15.9-24.0$ & $0.90(0.69)$ \\
\hline MRS & 17-18 Sep 2011 & $\mathrm{AB} 1, \mathrm{AB} 2, \mathrm{CT} 1$ & MBO & $0.03-0.11$ & $12.0-15.7$ & $0.07(0.03)$ \\
\hline MRS & 30 Jun-1 Jul 2011 & All except CT1 & MT & $0.05-4.57$ & $14.2-33.0$ & $1.30(1.26)$ \\
\hline MRS & 30 June-1 Jul 2011 & CT1 & MT & $2.97-11.43$ & $18.9-24.4$ & $15.67(5.88)^{\mathrm{c}}$ \\
\hline MRS & 7-8 Aug 2011 & $\mathrm{OB}, \mathrm{CT}$ & MT & $0.17-1.69$ & $22.9-36.6$ & $0.83(0.32)^{\mathrm{d}}$ \\
\hline MRS & 7-8 Aug 2011 & $\mathrm{AB}$ & MT & $0.12-1.42$ & $26.0-39.7$ & $0.40(0.14)^{\mathrm{d}}$ \\
\hline MRS & 17-18 Sep 2011 & $\begin{array}{l}\text { All, } \\
\text { except OB1 and AB1b }\end{array}$ & MT & $0.01-0.67$ & $12.0-24.0$ & $0.36(0.32)$ \\
\hline MRS & 17-18 Sep 2011 & OB1 & MT & $0.79-0.92$ & $10.5-12.6$ & $5.41(0.15)$ \\
\hline MRS & 17-18 Sep 2011 & $\mathrm{AB} 1 \mathrm{~b}$ & MT & $0.10-0.23$ & $11.4-13.4$ & $0.94(0.40)$ \\
\hline MRS & 30 Jun-1 Jul 2011 & $\begin{array}{l}\text { All, } \\
\text { except OB2 and CT1 }\end{array}$ & SQT & $0.004-0.090$ & $14.2-33.0$ & $0.073(0.044)$ \\
\hline MRS & 30 Jun-1 Jul 2011 & $\mathrm{OB} 2$ and $\mathrm{CT} 1$ & SQT & $0.157-0.340$ & $18.9-26.2$ & $0.707(0.172)$ \\
\hline MRS & 7-8 Aug 2011 & OB & SQT & $0.322-0.992$ & $25.2-33.8$ & $0.932(0.312)$ \\
\hline MRS & 7-8 Aug 2011 & $\mathrm{AB}$ and $\mathrm{CT}$ & SQT & $0.157-0.760$ & $22.9-39.7$ & $0.260(0.183)^{\mathrm{d}}$ \\
\hline MRS & 17-18 Sep 2011 & $\mathrm{OB}$ & SQT & $0.028-0.151$ & $10.5-24.0$ & $0.434(0.098)$ \\
\hline MRS & 17-18 Sep 2011 & $\mathrm{AB}$ and $\mathrm{CT}$ & SQT & $0-0.013$ & $11.4-18.0$ & $0.019(0.023)$ \\
\hline MRS & 30 Jun-1 Jul 2011 & all & OVOC & $0.008-0.458$ & $14.2-33.0$ & $0.165(0.139)$ \\
\hline MRS & 7-8 Aug 2011 & all except $\mathrm{AB} 2$ & OVOC & $0.023-0.439$ & $22.9-39.7$ & $0.161(0.102)$ \\
\hline MRS & 7-8 Aug 2011 & $\mathrm{AB} 2$ & OVOC & $0.590-3.139$ & $26.0-38.5$ & 1.908 (1.277) \\
\hline MRS & 15-17 Sep 2010 & $\mathrm{CT} 1, \mathrm{AB}$ & OVOC & $0-0.0004$ & $11.4-15.7$ & $0.0001(0.0001)$ \\
\hline MRS & 15-17 Sep 2010 & $\mathrm{CT} 2, \mathrm{OB} 2$ & OVOC & $0.001-0.008$ & $15.9-24.0$ & $0.003(0.002)$ \\
\hline MRS & 15-17 Sep 2010 & OB1 & OVOC & $0.007-0.009$ & $10.5-12.6$ & $0.008(0.001)$ \\
\hline
\end{tabular}

between clusters, further evidence that only one chemotype was present in the live trees at CP.

The ratios of SQT observed at CP tell a different story, with SQT compositions being somewhat unique across the three sample classes, and possibly also among individual stands (Table 5). $\alpha$-farnesene or e- $\beta$-farnesene was the dominant compound among the LG trees, while the BG trees had more heterogeneous SQT profiles, with increased importance of $\gamma$ - and $\delta$-cadinene, along with aromadendrene and $\alpha$-cuprenene in BG2. Interestingly, LG3 was similar to BG3; these two trees were growing relatively close to each other (but were still in different stands), while BG2 and BR2 also had similarities (and were growing just a few meters apart). Among the BR trees that were screened, BR1 had SQT ra- tios comprised almost entirely of $\gamma$-and $\delta$-cadinene, while BR2 (which emitted very little SQT) was dominated by $\gamma$ cadinene, aromadendrene, and $\alpha$-cuprenene.

\subsection{MRS, CO sampling results}

\subsubsection{Emission rates: 30 June-1 July}

There were no obvious differences in MBO ERs between any of the classes during this visit (Table 3). As previously observed in ponderosa pine (Gray et al., 2003), we saw a linear response in $\mathrm{MBO}$ emissions to temperature, with a slope of $0.472\left(R^{2}=0.79\right)$. Five of the trees screened had relatively low MT BERs (compared to other pine species as reported in 


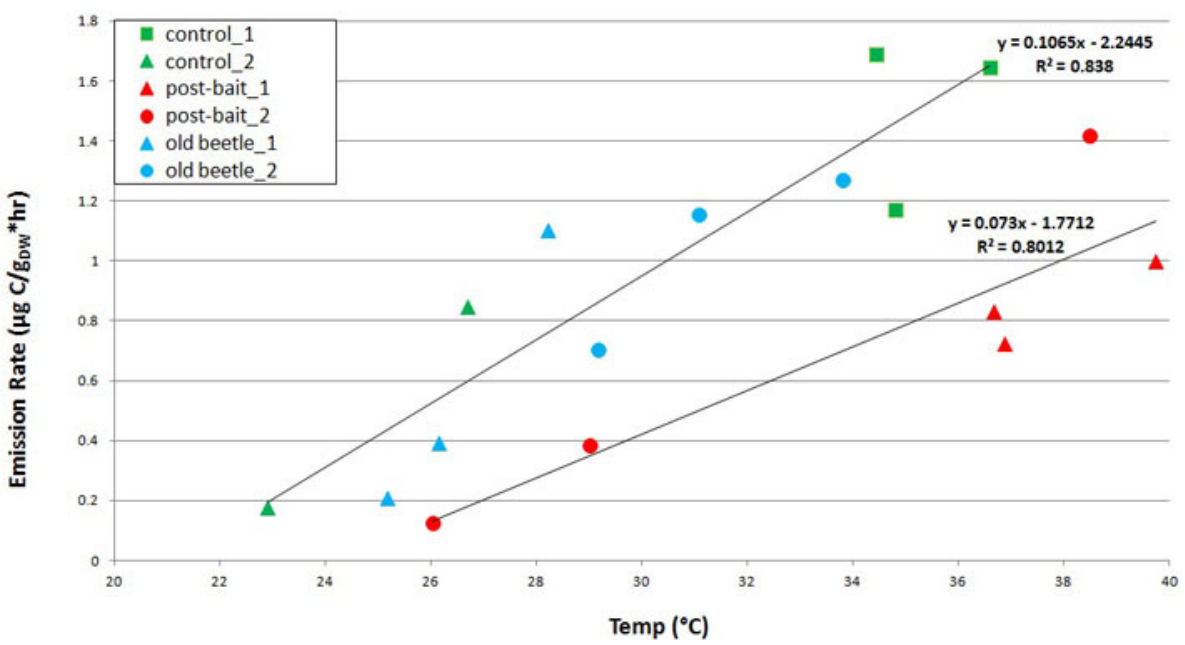

Fig. 3. MT emissions observed between 8-9 August at MRS, plotted as a function of temperature.

Helmig et al., 2007) while CT1 exhibited a higher MT BER (Table 3) with significant variability in MT BER among most of the trees (Table 6). One of the baited trees (OB2) and control tree 1 (CT1) exhibited significantly higher SQT BERs than the other four trees (Tables 3 and 7). Emissions of total OVOC (Table 3) exhibited an exponential temperature response $\left(R^{2}=0.64\right)$, with an average OVOC ER of 0.165 and average enclosure temperature of $24.4^{\circ} \mathrm{C}$.

\subsubsection{Emission rates: 7-8 August}

As observed during the first visit, there were no obvious differences in MBO emissions between any of the classes. MBO emissions exhibited a linear response to temperature, with a slope of $0.85,\left(R^{2}=0.66\right)$. MT emissions also exhibited a more or less linear relationship with temperature (Fig. 3) and less tree-to-tree variability in BERs compared to the 30 June1 July visit (Table 6). The slope obtained when a linear regression was performed on all the MT ER data (0.07) had a much lower $R^{2}$ value $(0.51)$ than when the baited trees were treated with a separate regression analysis: The baited trees had lower MT emissions than both control and oldbeetle trees at similar temperatures, and had a lower slope $\left(0.07, R^{2}=0.80\right)$ than control and old beetle trees $(0.11$, $R^{2}=0.84$, Fig. 3). During both the early August and midSeptember sampling days, the trees that had survived beetle attacks 1-2 yr prior to sampling (OB1, OB2) had the highest SQT BERs. OVOC emissions were similar to 30 June-1 July values for all trees except AB2 (Table 3).

Branch CT2 experienced very high temperatures (just over $40{ }^{\circ} \mathrm{C}$, the highest observed enclosure temperature; average ambient temperature at this time was $\sim 28^{\circ} \mathrm{C}$ ) during $\mathrm{Au}-$ gust sampling. The enclosure overheating, which lasted for $\sim 35$ min, occurred between collection of the first and second samples (both of which were within $3{ }^{\circ} \mathrm{C}$ of ambient values), and was caused by an extended period of direct sun- light incident on the enclosure. This offered an opportunity to evaluate the effects of a short duration of heat stress on both compound ratios and total emissions before and after exposure of the branch to high temperatures, as well as to evaluate longer-term effects on emissions since we returned to the site and sampled all of the branches again in midSeptember. Total MT emitted before and after the heat event exhibited temperature-related differences, which were similar to the quantities and temperature dependencies of MT emitted by OB1 (which did not experience heat stress), suggesting that short-term heat stress did not substantially affect the quantity of MT emitted, although the ratios of MT and SQT changed a lot before and after the heat event (not shown). The total amount of SQT emitted following the heat event was almost the same as the pre-heating emission, despite the fact that the temperature was $1.3^{\circ} \mathrm{C}$ warmer in the latter sample. Ratios of OVOC did not change much, and the branch emitted about the same total amounts of OVOC as other branches (except AB2, which emitted more OVOC than any other branch). Tree AB1 also experienced substantial overheating (average enclosure temperature was $\sim 38^{\circ} \mathrm{C}$ throughout sampling), and trees $\mathrm{AB} 2$ and $\mathrm{CT} 1$ experienced moderately elevated enclosure temperatures during August sampling. Therefore, the ERs given in Table 3 and the compound speciation data in Tables 4-5 may reflect some degree of stress-induced emissions.

\subsubsection{Emission rates: 17-18 September}

The two OB trees, CT2, and the secondary branch sampled from AB1 (AB1b) had higher MBO ERs than the other branches screened (Table 3). CT2 and AB2 emitted comparable amounts of MBO to what was measured in $\mathrm{AB} 1 \mathrm{~b}$ and OB1, although the temperatures these branches experienced were warmer than what was observed in enclosures $\mathrm{AB} 1 \mathrm{~b}$ and $\mathrm{OB} 1$. Interestingly, the group of branches with 


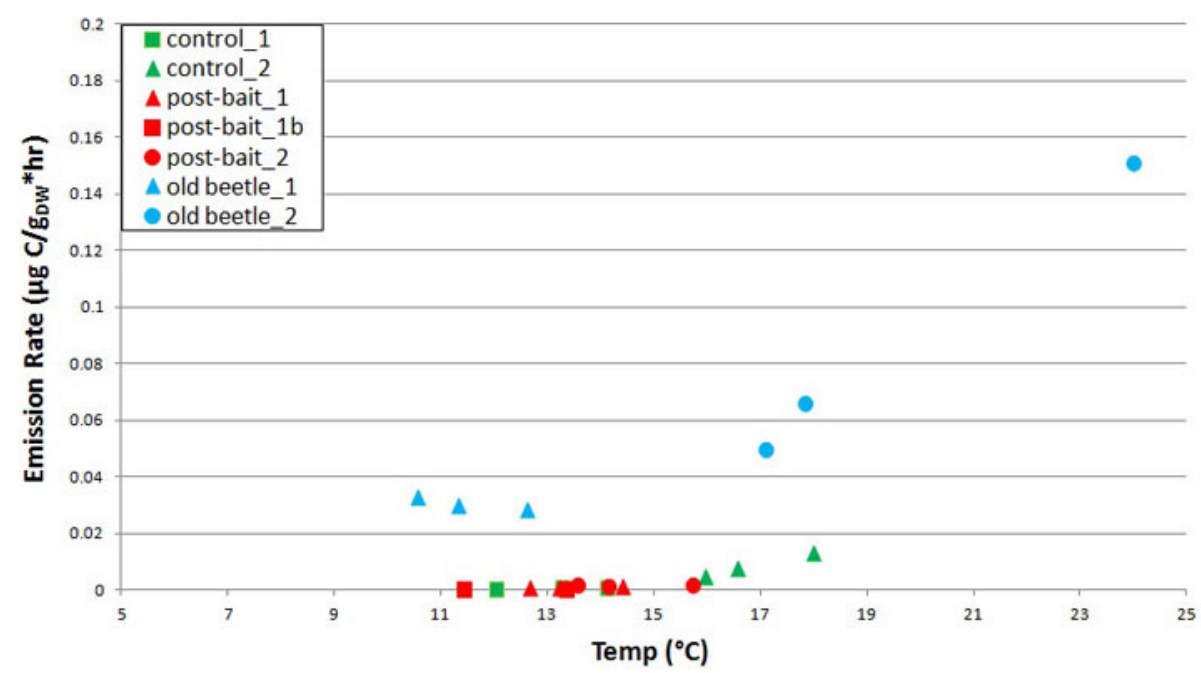

Fig. 4. SQT emissions observed during the last MRS sampling visit (17-18 September), plotted as a function of temperature.

the lowest $\mathrm{MBO}$ emissions in mid-September (CT1, AB1 and $A B 2$ ) experienced the most heat stress from enclosure overheating in August. A second branch from baited tree \#1 ("AB1b") was sampled during the September sampling period to evaluate potential long-term effects on emissions following a period of heat stress, as the primary branch sampled from this tree was exposed to the longest period $(\sim 4.5 \mathrm{~h}$; the entire duration of the sampling period for this branch) of heat stress during August sampling. MT ratios were nearly identical between this branch and the primary branch sampled from the tree. MT ERs were slightly higher in branch $\mathrm{B}$ than in the other branches experiencing similar temperatures (branches AB1 and CT1), but still lower than what was emitted by OB1, which experienced similar enclosure temperatures during this visit (and no heat stress during August sampling). MT emissions mostly displayed a linear relationship with temperature, with a slope of $0.11\left(R^{2}=0.78\right)$, excluding OB1, which had a significantly higher BER than the other branches (Table 6), as well as the secondary enclosure placed on a previously unsampled branch from $\mathrm{AB} 1$ (AB1b), which had a BER $\sim 2.6$ times higher than the other enclosures. The enclosures exhibiting the lowest MT emissions in September were the same enclosures that experienced the most heat stress during the August measurements. SQT emissions measured in September were lower than August emissions for all trees, with the old-beetle branches emitting $\sim 5$ 40 times more SQT than other trees at similar temperatures (Fig. 4, Table 3), including the previously unsampled branch from one of the baited trees (i.e., AB1b, which did not emit SQT, although tiny amounts were emitted from AB1), implying that the observed differences were not consequences of enclosure overheating during the August campaign. SQT BERs for the OB trees were also significantly higher than the other trees (Table 6). OVOC emissions were $<0.0004$ for all enclosures other than the two OB trees and CT2. Tree OB1 emitted $\sim 22$ times more OVOC during the 17-18 September measurements than other trees at similar enclosure temperatures.

\subsubsection{Seasonal MT, SQT, and OVOC speciation profiles}

MT species (Table 4) identified in each tree during the course of the campaign exhibited significantly more tree-to-tree variability than what was observed at the $\mathrm{CP}$ site. During late June/early July, $\beta$-pinene was the dominant MT emitted by three of the trees (OB1, OB2 and BB1), $\beta$-phellandrene the dominant MT emitted by both trees selected to be controls (CT1, CT2), and 3-carene the dominant MT emitted by BB2. Though ratios changed somewhat during the August campaign (Table 4), the MTs (which were dominant in the first sample period) returned to being dominant in the September samples, except in CT1 (which was also by far the highest MT emitter). The baited trees both exhibited a decrease in the richness of MT chemical species emitted by the end of the campaign, with an average of $10 \mathrm{MT}$ observed on 1718 September compared to 16 during 30 June- 1 July. The control trees both also exhibited a slight decrease (average of 14 MT species observed on 17-18 September compared to 16 during 30 June-1 July), while the old-beetle trees did not show a decrease in MT diversity. A secondary enclosure that was placed on a previously unsampled branch from baited tree \#1 (i.e., AB1b) during the September measurements had a very similar MT profile as the dedicated branch from this tree.

When k-means clustering was applied to the September MT compositions for all trees, and the resulting SSE for different cluster solutions was tested against the SSE results of 250 randomized versions of the original data, the results indicated strong solutions for 3-5 clusters depending on the lumping scheme used (i.e., using either the three 


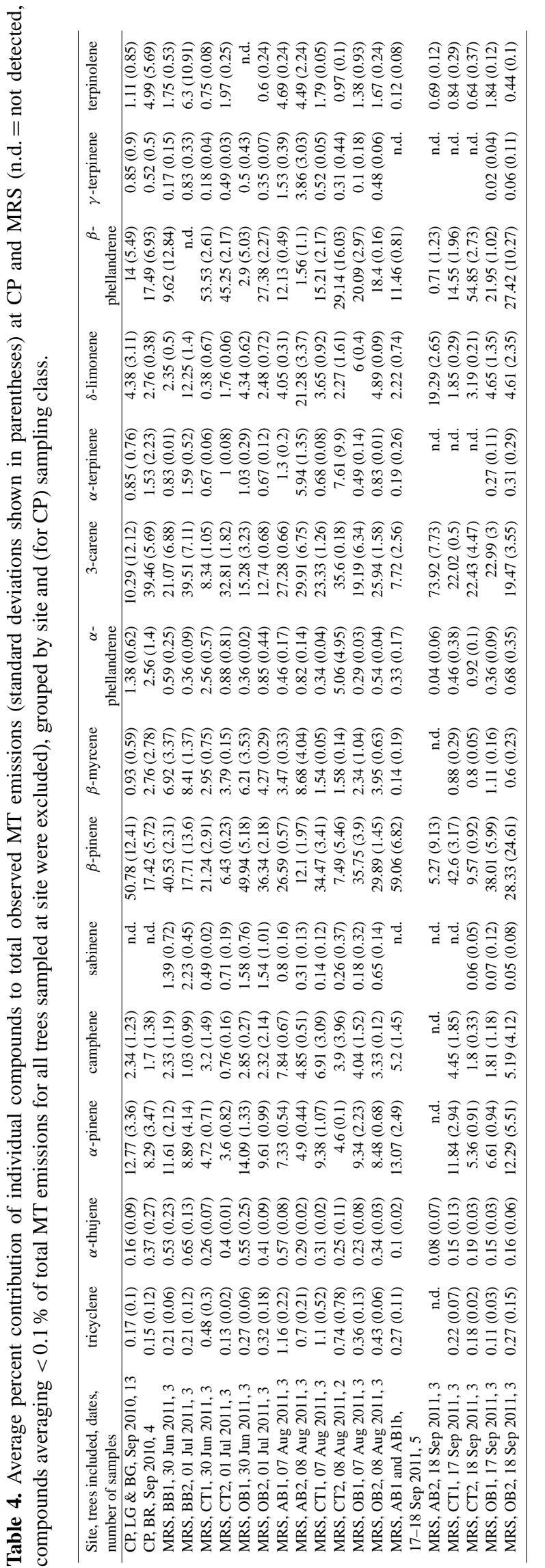

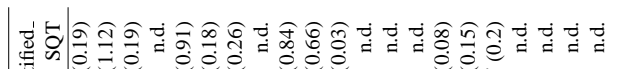

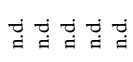

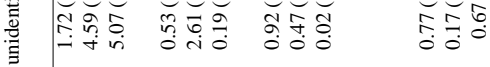

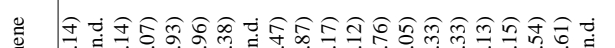

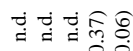

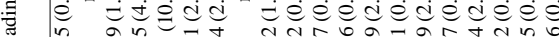

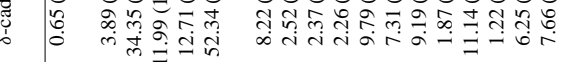

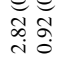

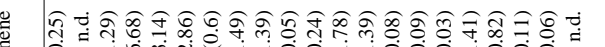

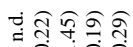
F

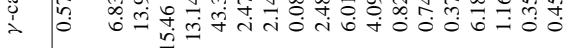

子ᄒ

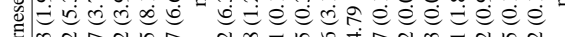

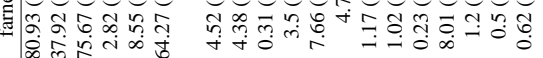

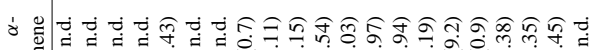

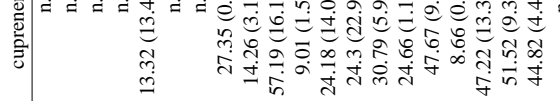

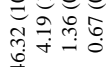
j子

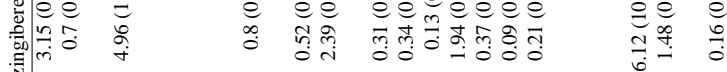

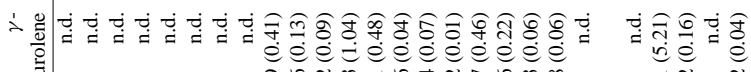

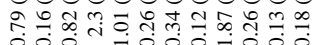
可

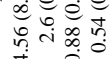

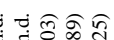

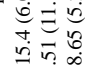

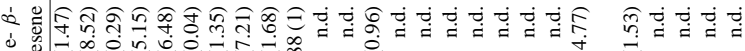

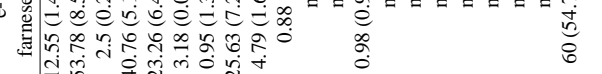
in

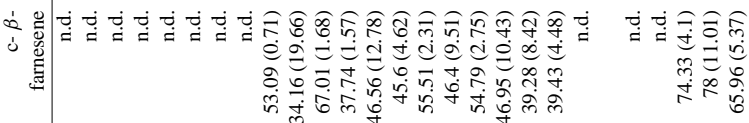

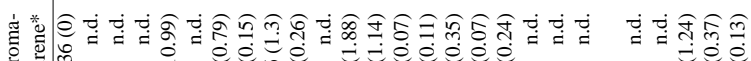

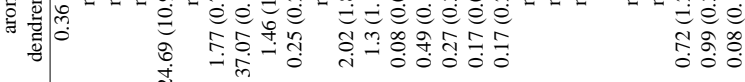

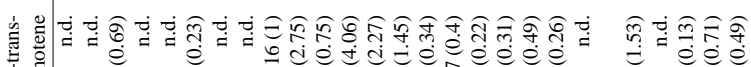

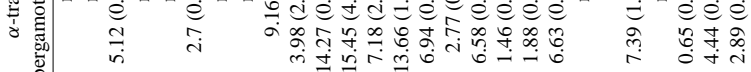
子े

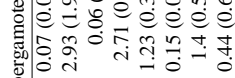

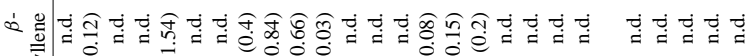
商

薝

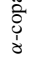

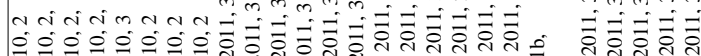

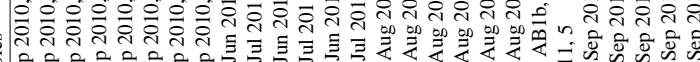

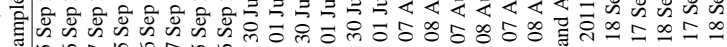

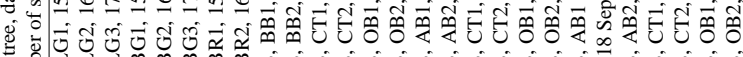

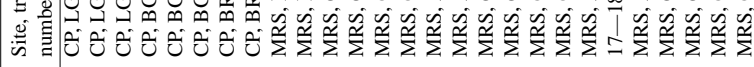


Table 6. Two-sided t-test results (reported as p-values) between individual tree MT and SQT BERs during the first, second, and third sampling visits at MRS, and between sampling classes at CP (bold lettering indicates significance at the $95 \%$ confidence level). The BR sample class at $\mathrm{CP}$ and August emissions from tree CT-2 at MRS were excluded from statistical analyses due to small sample sizes.

\begin{tabular}{|c|c|c|c|c|c|c|c|c|c|c|c|}
\hline \multicolumn{6}{|c|}{ MRS 30 Jun-1 Jul MT } & \multicolumn{6}{|c|}{ MRS 30 Jun-1 Jul SQT } \\
\hline tree code & BB2 & CT1 & $\mathrm{CT} 2$ & OB 1 & OB2 & tree code & BB2 & CT1 & $\mathrm{CT} 2$ & OB1 & OB2 \\
\hline BB1 & 0.7775 & 0.04641 & 0.006056 & 0.2778 & 0.03485 & BB1 & 0.03432 & $2.10 \times 10^{-5}$ & 0.05103 & 0.0694 & 0.04678 \\
\hline BB2 & & 0.04562 & 0.007741 & 0.8456 & $\mathbf{0 . 0 3 5 8 1}$ & BB2 & & 0.00011 & 0.2163 & 0.1222 & 0.02161 \\
\hline CT1 & & & 0.01918 & 0.04581 & 0.01957 & CT1 & & & $3.54 \times 10^{-5}$ & $2.78 \times 10^{-5}$ & 0.3808 \\
\hline CT2 & & & & 0.004998 & 0.925 & CT2 & & & & 0.5278 & 0.01531 \\
\hline OB1 & & & & & 0.02972 & OB1 & & & & & 0.01406 \\
\hline \multicolumn{6}{|c|}{ MRS 7-8 Aug MT } & \multicolumn{6}{|c|}{ MRS 7-8 Aug SQT } \\
\hline tree code & AB2 & CT1 & $\mathrm{CT} 2$ & OB1 & OB2 & tree code & $\mathrm{AB} 2$ & CT1 & $\mathrm{CT} 2$ & OB1 & $\mathrm{OB} 2$ \\
\hline $\mathrm{AB} 1$ & 0.8991 & 0.00986 & & 0.3523 & 0.003709 & $\mathrm{AB} 1$ & 0.132 & $9.62 \times 10^{-5}$ & & 0.04251 & 0.04514 \\
\hline $\mathrm{AB} 2$ & & 0.0406 & & 0.3494 & 0.0293 & AB2 & & 0.3302 & & 0.04597 & 0.08523 \\
\hline CT1 & & & & 0.6696 & 0.9846 & CT1 & & & & 0.05665 & 0.06575 \\
\hline OB1 & & & & & 0.6561 & OB1 & & & & & 0.4565 \\
\hline \multicolumn{6}{|c|}{ MRS 17-18 Sep 2011 MT } & \multicolumn{6}{|c|}{ MRS 17-18 Sep SQT } \\
\hline tree code & AB2 & CT1 & CT2 & OB1 & OB2 & tree code & $\mathrm{AB} 2$ & CT1 & CT2 & OB1 & OB2 \\
\hline $\mathrm{AB} 1$ & 0.04071 & 0.9706 & 0.0726 & $4.54 \times 10^{-7}$ & 0.1069 & $\mathrm{AB} 1$ & 0.09668 & $\mathbf{0 . 0 1 2 5 3}$ & 0.0496 & 0.01746 & 0.002582 \\
\hline $\mathrm{AB} 2$ & & 0.1572 & 0.02322 & $5.56 \times 10^{-7}$ & 0.03098 & $\mathrm{AB} 2$ & & 0.02455 & 0.0209 & 0.01776 & $4.47 \times 10^{-5}$ \\
\hline CT1 & & & 0.1235 & $9.08 \times 10^{-7}$ & 0.05372 & CT1 & & & 0.04349 & 0.01721 & 0.002536 \\
\hline CT2 & & & & $1.63 \times 10^{-6}$ & 0.1342 & $\mathrm{CT} 2$ & & & & 0.00273 & 0.0001341 \\
\hline OB1 & & & & & $4.77 \times 10^{-5}$ & OB1 & & & & & 0.1577 \\
\hline \multicolumn{12}{|c|}{ CP 15-17 Sep 2010} \\
\hline \multicolumn{3}{|c|}{ MT BER } & \multicolumn{3}{|c|}{ MT fraction } & \multicolumn{2}{|c|}{ SQT BER } & \multicolumn{4}{|c|}{ SQT fraction } \\
\hline tree code & BG & $\mathrm{BR}$ & tree code & BG & BR & tree code & BG & $\mathrm{BR}$ & tree code & BG & BR \\
\hline LG & 0.7853 & & LG & 0.2438 & & LG & 0.09836 & & LG & 0.03284 & \\
\hline
\end{tabular}

or five most dominant MT or all MT detected), indicating the presence of 3-5 MT chemotypes at MRS in September (irrespective of infestation status). The PCA plots obtained for the various cluster solutions and lumping schemes also indicated strong clusters, further evidence that several chemotypes were present in the live trees at MRS. When three clusters were selected, the resultant chemotypes could be classified according to their dominant MT $(\beta$-pinene, $\beta$ phellandrene, or 3-carene). When 5 clusters were used, additional "mixed" chemotypes emerged that were formed when the average contribution to total MT from the second-most dominant MT was within a factor of two of the dominant compound.

Table 5 depicts the SQT species identified in each tree during the campaign. In both the 30 June-1 July and 7-8 August sample periods, z- $\beta$-farnesene and $\alpha$-farnesene were the dominant SQT emitted from all of the trees. Similar to observed MT behavior, the baited trees exhibited a decrease in the richness of SQT chemical species emitted by the end of the campaign. Both baited trees had completely different SQT profiles in September (comprised mostly of e- $\beta$ farnesene), compared with samples from the first two visits and with the other trees. Control tree \#1, which had SQT profiles similar to the other trees during the first two measurement periods, also had a radically different SQT profile dur- ing the final sampling visit, dominated by $\delta$ - and $\gamma$-cadinene, a profile that was similar to that of the MPB-infested trees at Chimney Park.

OVOC profiles (not shown) varied between individual trees and through time, and, as observed for MT and SQT ratios, the old beetle trees also had the highest average OVOC diversity as a group during the final sampling visit. During the first visit eucalyptol was the dominant compound in BB1 and both OB trees, while amyl acetate was dominant in CT2. OVOC measured from CT1 was dominated by methyl salicylate and had a significant contribution $(\sim 28 \%)$ from pinocarvone, which was not found in amounts $>5 \%$ in any other tree during the campaign. Linalool was the dominant OVOC observed in the first post-baiting measurements (mid-August) from both baited trees as well as in CT1; amyl acetate was the major OVOC emitted from OB1 and CT2 (which also emitted $\sim 31 \%$ methyl salicylate), and OB2 was dominated by eucalyptol and linalool. Camphor dominated September OVOC emissions all of the branches except OB1 and OB2, in which amyl acetate and eucalyptol were the dominant compounds, respectively. 


\section{Discussion}

This screening study highlights differences in the chemical diversity of emissions from lodgepole pines in two forest sites impacted differently by the MPB, and also presents the seasonal variation observed in BVOC emissions from apparently healthy trees versus trees in different stages of MPB attack. At the Chimney Park, WY site, where MPB-related mortality has been high, we found remarkable homogeneity in MT speciation profiles among the various live lodgepole trees studied, irrespective of whether or not they had been infested by MPB. The ostensibly dead (i.e., red-needled) trees at the Chimney Park site emitted negligible amounts of MBO and had different MT profiles than live trees. This may simply reflect a difference in the MT speciation profiles of woody and foliar tissues. Ratios of SQT detected at that site were more unique to the studied groups (i.e., uninfested trees had a different profile than infested but still living trees, etc.), and possibly reflective of the stage of infestation, although within-stand differences may also have been present. The SQT $\gamma$ - and $\delta$-cadinene seemed to correlate with MPB infestation at CP. Measurements conducted at this site suggest that trees that might be expected to succumb to MPB attack may have lower SQT emission capacities than their non-infested counterparts.

Lodgepole trees screened at the University of Colorado Mountain Research Station (MRS) site exhibited significantly more diverse MT profiles, even though the trees that were sampled at this site were growing much nearer to each other and were also closer in age than the Chimney Park trees. At the MRS site, lodgepoles appear to be more resilient to the MPB and/or its fungal symbiont, the blue stain fungus (of which there are at least two species). Although, to our knowledge, little is known about whether specific chemotypes of Pinus contorta are better equipped to survive MPB attack, it has been known for some time that MT emission profiles observed both in tree resin and in emissions are unique between most subspecies/varieties of lodgepole (e.g., Zavarin et al., 1969; Lusebrink et al., 2011). Even within a seemingly homogenous zone, several chemotypes of a given species may be present, and the relative ratios of compounds detected in ambient air have been observed to reflect this diversity (Bäck et al., 2012).

SQT profiles from MRS trees in both late June/early July and early August showed a high degree of homogeneity, although samples collected in mid-September (during the same time of year that the trees at Chimney Park were sampled) suggest that, at some point in the $\sim 6$ weeks following MPB attack, SQT profiles change in newly infested trees. Also, the trees that survive attack (from previous years) may eventually return to their "pre-attack" SQT profiles (based on the observation that survivors of MPB attack had profiles similar to uninfested trees). There were no obvious class-related differences in SQT emissions at the MRS in late June/early July sampling, but during both the early-August and mid-
September visits to MRS, the trees that had survived beetle attacks $1-2 \mathrm{yr}$ prior to sampling exhibited the highest temperature-adjusted SQT emission capacities, which was opposite the trend observed at CP. The two beetle attack survivors sampled at MRS in early August did not experience enclosure heat stress, while the other four enclosures (placed on two baited and two control trees) did experience varying degrees of enclosure over-heating. However, the midSeptember sampling period included an enclosure placed on a previously unsampled branch from one of the baited trees, and results from this enclosure showed no SQT emissions. Also, one of the control trees experienced elevated enclosure temperatures for only $\sim 35$ min during the August measurements, and still exhibited substantially lower SQT emissions than the trees that had survived MPB attack in prior years. The reasons why elevated SQT emissions were seen in the MPB survivors only during mid- and late-season sampling are unknown, but it could be a response to beetle activity at the site, since MPBs were not observed at the site during the early season sampling campaign at MRS.

Emissions of MBO from vegetation are both light- and temperature-driven and decline with needle age (Gray et al., 2003). This was not observed between the late June/early July versus early August campaigns, although MBO emission capacities (at comparable temperatures) were lower in mid-September. The observations that mid-September MBO and MT emissions were lower among branches that had experienced heat stress lead us to conclude that exposure to a relatively short duration $(\sim 30 \mathrm{~min}$ to several hours $)$ heat event may reduce longer-term MBO and MT (and possibly also SQT) emission capacity, although this effect is not definitive. Both MT and SQT ratios did change in response to heat stress, although this was likely a short-term effect.

There was a general pattern across all compound classes studied that the number of compounds detected in each class declined during the growing season, with the greatest decline observed in newly infested trees and the least decline in survivors of MPB-attack from previous years. Other than a tree potentially infested with an unknown pathogen at MRS (see below), there were not significant differences in total OVOC emissions between the trees, except during the last measurement days, when the MPB survivors emitted more OVOC than their counterparts.

We postulate that one of the two control trees at the MRS site (CT1) may have been infested with an unknown pathogen. This tree exhibited by far the highest MT emission capacity and one of the highest SQT emission rates during the first sampling visit. By now it has been well documented that biotic stressors can enhance emissions of both MT and SQT (Huber et al., 2004; Duhl et al., 2008). Although stressinduced emissions bursts have also been observed following enclosure installation (e.g., Arey et al, 1995), all enclosures were allowed to equilibrate prior to sampling for a minimum of $16 \mathrm{~h}$ to minimize this risk. Enclosure temperatures remained very close to ambient values for all trees sampled 
during this first visit, so heat stress was ruled out as a cause of the unusual emissions observed from CT1, which also emitted methyl salicylate as its dominant OVOC during the first sampling period (unlike any other tree sampled), a compound whose emissions are known to be enhanced in many tree species in response to both biotic and abiotic stressors (e.g., Kännaste et al., 2008; Joó et al., 2011). This tree also emitted $\sim 30-50$ times more o-cymene and p-cymenene than any of the other trees sampled (data not shown) and had unusual behavior in both MT and SQT profiles through the course of the growing season. Whereas the dominant MT observed in the early part of the season was also dominant towards the end of the growing season, in this tree alone a different MT was dominant during the final sampling visit. Bäck et al. (2012) found that, despite seasonal changes observed in MT profiles among different chemotypes of Scots pine ( $\mathrm{Pi}$ nus sylvestris L.), the dominant compound did not cease to be dominant. Also, the SQT profile observed in this tree at the end of the campaign was singular, but was interestingly comprised mostly of the same two compounds found to be associated with MPB infestation at the Chimney Park site $(\delta$ and $\gamma$-cadinene).

Some evidence suggests that fire injury in Pinus contorta can lessen induced defenses against MPB (Powell and Raffa, 2011). Fires have not been common at MRS in the last few hundred years, nor at CP in the last $100 \mathrm{yr}$ (Table 1). None of the trees sampled had obvious fire damage, and so this effect is not suspected to play a role in observed differences between Chimney Park and MRS. It is not known which species of blue stain fungus predominate either site, while it is known that some species are more virulent than others (Lusebrink et al., 2011), and so this factor cannot be excluded when pondering the difference in apparent MPB resilience between the sites.

The effects of soil type and nutrient availability on emissions from lodgepole are unknown, though Ormeño et al. (2007) observed higher emissions of $\alpha$-pinene from a Mediterranean pine species ( $P$. halepensis) growing in calcareous versus siliceous soils. At both the MRS and CP sites, soils are dominated by Typic Cryocrepts and Typic Cryoboralfs (Table 1, Knight, 1991; Birkeland et al., 2003; Veblen and Donnegan, 2005); soils at the MRS study site are predominantly of a sandy loam texture (with 10-15\% clay content, Birkeland et al., 2003) with large cobbles and rocks present. The mineral soils at MRS are overlain by a fairly shallow organic layer $(5-10 \mathrm{~cm})$, which is also overlain by a forest litter layer that has high spatial variability depending largely on canopy conditions. Soils at the CP site are predominantly of a sandy clay loam texture and exhibit more vertical stratification than do the soils at the MRS site. Similar to the MRS site, CP soils under lodgepole pine stands have a significant litter layer covering a decayed organic layer of 5$10 \mathrm{~cm}$ thickness (D. Gochis, personal communication, 2012). The similarity of the soil types at the two sites makes it un- likely, in our opinion, that differences in observed emissions between the sites are driven by local geology.

The presence or absence of water stress must be considered when evaluating differences between the sites, as water deficit has been shown to decrease emissions of MT in lodgepole seedlings and may also affect tree resistance to MPB (Lusebrink et al., 2011; Safranyik et al., 2010). We analyzed precipitation data for the 5- and $10-y r$ period prior to the start of sampling at both the Chimney Park and MRS sites (using PRISM precipitation data, PRISM Climate Group, Oregon State University, http://prism.oregonstate.edu, created 4 Feburary 2004), and found that both sites had received at or above $100 \%$ of their 1971-2000 average values during the study time periods (Table 1), although it should be noted that average annual precipitation at $\mathrm{CP}$ is $\sim 60 \%$ of the average for MRS. The fact that the sites were relatively moist during the recent period compared to their long-term climatologies is not intended to dispute that severe punctuated drought may have been a possible causative mechanism for the MPB outbreak that caused widespread tree mortality as has been suggested by others (e.g., Bentz et al., 2010; Breshears et al., 2005). Instead, it is only presented to illustrate the recent hydroclimatic context of the summers when BVOC sampling was performed. Lastly, it is noted that the seasonal soil moisture in this region is largely modulated by strong springtime snowmelt followed by a long gradual drydown throughout the summer growing season with periodic pulses from summer rainfall events. Both sites exhibited this typical behavior (not shown) during the 2010 and 2011 sampling years.

In addition to the abiotic factors that might contribute to observed differences in emissions profiles and tree mortality at each site, relevant biotic factors such as site-specific beetle pressure should also be considered when seeking to explain observed differences. The beetle pressure at $\mathrm{CP}$ has clearly been significant given the high mortality at that site (Table 1). It also appears that MRS has experienced high beetle pressure since, despite the fact that MPB-related lodgepole mortality has been low, limber pine mortality has been quite high (Table 1), and average pitch tube counts among naturally attacked trees at MRS were actually higher than what was observed at CP (Table 1). Although pitch tube counts are not a complete measure of beetle pressure or tree defenses, beetle flight data taken from beetle traps at MRS (which is not available for $\mathrm{CP}$ ) suggest substantial beetle presence at that site with the length of the flight season varying from 95 to 115 days between 2008-2011. Additionally, high levels of MPB activity ( $>10$ individuals/day in single traps or on individual trees) were measured consistently throughout July and August 2009-2011. Importantly, there were sufficient numbers of MPB still in flight in September of all years to successfully attack and kill trees en masse (S. Ferrenbeg, personal communication, 2012). If it cannot be demonstrated that beetle pressures and/or abiotic factors differ substantially between the sites, it seems reasonable to 
ask whether the trees at MRS may be more genetically diverse than their counterparts at $\mathrm{CP}$ or other locations with higher MPB mortality. Analyses of monoterpene resin chemistry indicate that MRS specimens have higher heterozygosity as compared with a number of other stands sampled (Ferrenberg, unpublished data), although $\mathrm{CP}$ was not included in these resin samples. Nonetheless, these observations, the site-specific comparisons of other biotic and abiotic factors (above), and the observed differences in MT chemodiversity between the sites suggest that the trees sampled at MRS may be more diverse than many other lodgepole populations.

The observations made in this study have unclear consequences on our understanding of feedbacks in plant-insect interactions (since MPBs are thought to respond mainly to BVOC emanating from trunks), whereas the potential for MPB-driven effects on regional air quality and secondary organic aerosol (SOA) formation from both trunk- and canopylevel emission changes is a more obvious use of the data. Since SOA yields of different MT and SQT species vary by more than a factor of two (Ng et al., 2006), a change in MT or SQT speciation can result in a substantial change in the amount of SOA produced from these emissions. The changes in MT speciation of the newly infested trees at MRS include one case where the average SOA yield would increase, due to a higher proportion of 3-carene and $\delta$-limonene, and another case where the average SOA yield would be expected to decrease due to the increase in the contribution of $\beta$-pinene. Reactivities of the SQT species (relative to the major atmospheric oxidants) observed in this study are not well constrained, and further inquiry into the aerosol formation potentials of the SQT cadinenes (which may become elevated in MPB-infested trees experiencing MPB-related decline) and farnesenes is warranted. The predicted halflives of $\alpha$ - and $\beta$-farnese with respect to $\mathrm{OH}$ and $\mathrm{O}_{3}$ are $\sim 60-70 \%$ of what is predicted for $\delta$ - and $\gamma$-cadinene (http: //www.epa.gov/opptintr/exposure/pubs/episuite.htm). Therefore, the expected SOA yield might be lower if the cadinenes are emitted in increased proportions by declining trees. Also of consequence are the total emissions of the various compound classes, though these impacts need to be more fully qualified before such extrapolations can be made. Amin et al. (2012) observed higher trunk-level concentrations of the MT $\beta$-phellandrene and total MT near infested lodgepole trees as compared to healthy trees and suggested a possible increase in SOA from the MPB epidemic due to both increased MT concentrations near infested trees and to the reactivity of $\beta$-phellandrene compared with other MT, although it is also necessary to consider that, as soon as needles die, there will be significant loss of SOA-formation potential from MBO since this compound is produced de novo. MBO is thought to make substantial contributions to SOA formation in areas where it is emitted in great quantities, such as from the pine forests of western North America (Steiner et al., 2007).
A caveat to the results presented in this study is the low number of individuals screened, which limits the validity of making extrapolations based on the data we have presented. However, the stark contrast evident between the two sites speaks for itself, and several statistically significant relationships have been observed. These findings, especially when combined with other relevant studies, beg for more research into relationships between lodgepole pine chemodiversity and MPB. Additionally, future measurements should focus on quantifying the potential magnitude and direction of change in altered BVOC emissions and thus possible consequences for regional atmospheric chemistry.

\section{Conclusions}

Whether the relatively high degree of variability in monoterpene profiles observed in lodgepole pine trees growing at the MRS site is related to the MPB resistance observed there remains uncertain. Owing to the low number of individuals screened, this study also leaves open the question of to what degree emissions and ratios of various BVOC compound classes emitted from the forest are in response to beetle activity versus natural tree-to-tree variation and seasonal changes. We observed fewer compounds in each compound class (monoterpenes, MTs; oxygenated VOC, and sesquiterpenes, SQTs) studied near the end of the growing season as compared to earlier in the season at MRS. Results from our study suggest that, in lodgepole pine trees, high proportions of certain SQT (i.e., $\delta$ - and $\gamma$-cadinene) may be indicative of poor overall fitness, caused by either unknown pathogens (as may have been the case in one tree sampled at MRS), or by the decline following successful MPB infiltration (as seen at CP). Changes in SQT composition from newly infested trees may take weeks to become apparent, and may not persist in trees that survive attack. Our results suggest that lodgepole trees that do survive may have long-term increases in SQT emission capacities, but only during certain times of the growing season, whereas stands of trees that succumb to the MPB/blue stain complex (based on CP results) may have reduced SQT emissions relative to healthy trees (at least towards the end of the growing season). Since SQTs have higher SOA yields than most other BVOC emitted by vegetation, this could have significant implications for regional air quality and aerosol formation at certain times of the year. Future research should focus on understanding MPB effects on chemodiversity and, conversely, the effects of lodgepole pine chemodiversity on MPB resilience, as well as on quantifying the potential magnitude and direction of MPB-driven changes in BVOC emissions and consequences for regional atmospheric chemistry. 
Acknowledgements. The National Center for Atmospheric Research is sponsored by the US National Science Foundation. T. Duhl and D. Gochis acknowledge support from NSF-ETBC grant 0910961.

Edited by: P. Stoy

\section{References}

Allen, C. D., Macalady, A. K., Chenchouni, H., Bachelet, D., McDowell, N., Vennetier, M., Kitzberger, T., Rigling, A., Breshears, D. D., Hogg, E. H., Gonzalez, P., Fensham, R., Zhang, Z., Castro, J., Demidova, N., Lim, J.-H., Allard, G., Running, S. W., Semerci, A., and Cobb., N.: A global overview of drought and heatinduced tree mortality reveals emerging climate change risks for forests, Forest Ecol. Manag., 259, 660-684, 2010.

Amin, H., Atkins, P. T., Russo, R. S., Brown, A. W., Sive, B., Hallar, A. G., and Huff Hartz, K. E.: Effect of bark beetle infestation on secondary organic aerosol precursor emissions, Environ. Sci. Technol., 46, 5696-5703, 2012.

Arey, J., Crowley, D. E., Crowley, M., Resketo, M., and Lester, J.: Hydrocarbon emissions from natural vegetation in California's South Coast Air Basin, Atmos. Environ., 29, 2977-2988, 1995.

Bäck, J., Aalto, J., Henriksson, M., Hakola, H., He, Q., and Boy, M.: Chemodiversity of a Scots pine stand and implications for terpene air concentrations, Biogeosciences, 9, 689-702, doi:10.5194/bg-9-689-2012, 2012.

Bentz, B. J., Régnière, J., Fettig, C. J., Hansen, E. M., Hayes, J. L., Hicke, J. A., Kelsey, R. G., Negrón, J. F., and Seybold, S. J.: Climate change and bark beetles of the western United States and Canada: Direct and indirect effects, Bioscience, 60, 602-613, 2010.

Billings, R. F., Gara, R. I., and Hrutfiord, B. F.: Influence of ponderosa pine resin volatiles on the response of Dendroctonus ponderosae to synthetic trans-verbenol, Environ. Entomol., 5, 171179, 1976.

Birkeland, P. W., Shroba, R. R., Burns, S. F., Price, A. B., and Tonkin, P. J.: Integrating soils and geomorphology in mountains - an example from the Front Range of Colorado, Geomorphology, 55, 329-344, 2003.

Breshears, D. D., Cobb, N. S., Rich, P. M., Price, K. P., Allen, C. D., Balice, R. G., Romme, W. H., Kastens, J. H., Floyd, M. L., Belnap, J., Anderson, J. J., Myers, O. B., and Meyer, C. W.: Regional vegetation die-off in response to global-change-type drought, $\mathrm{P}$. Natl. Acad. Sci. USA, 102, 15144-15148, 2005.

Clow, D. W., Rhoades, C., Briggs, J., Caldwell, M., and Lewis Jr., W. M.: Responses of soil and water chemistry to mountain pine beetle induced tree mortality in Grand County, Colorado, USA, Appl. Geochem., 26, 174-178, doi:10.1016/j.apgeochem.2011.03.096, 2011.

Duhl, T. R., Helmig, D., and Guenther, A.: Sesquiterpene emissions from vegetation: a review, Biogeosciences, 5, 761-777, doi:10.5194/bg-5-761-2008, 2008.

Edburg, S. L., Hicke, J. A., Brooks, P. D., Pendall, E. G., Ewers, B. E., Norton, U., Gochis, D. J., Gutmann, E. D., and Meddens, A. J.: Cascading impacts of bark beetle-caused tree mortality to coupled biogeophysical and biogeochemical processes, Front. Ecol. Environ., 10, 416-424, 2012.
Gara, R. I., Littke, W. R., and Rhoades, D. F.: Emission of ethanol and monoterpenes by fungal infected lodgepole pine trees, Phytochemistry, 34, 987-990, 1993.

Gray, D. W., Lerdau, M. T., and Goldstein, A. H.: Influences of temperature history, water stress, and needle age on methylbutenol emissions, Ecology, 84, 765-776, 2003.

Guenther, A. B., Zimmerman, P. R., Harley, P. C., Monson, R. K., and Fall, R.: Isoprene and monoterpene emission rate variability: Model evaluations and sensitivity analyses, J. Geophys. Res.Atmos., 98, 12609-12617, doi:10.1029/93JD00527, 1993.

Helmig, D., Ortega, J., Duhl, T., Tanner, D., Guenther, A., Harley, P., Wiedinmyer, C., Milford, J., and Sakulyanontvittaya, T.: Sesquiterpene emissions from pine trees: Identifications, emission rates, and flux estimates for the contiguous United States, Environ. Sci. Technol., 41, 1545-1553, 2007.

Huber, D. P., Ralph, S., and Bohlmann, J.: Genomic hardwiring and phenotypic plasticity of terpenoid-based defenses in conifers, J. Chem. Ecol., 30, 2399-2418, 2004.

Joó, É., Dewulf, J., Amelynck, C., Schoon, N., Pokorska, O., Šimpraga, M., Steppe, K., Aubinet, M., and Van Langenhove, H.: Constitutive versus heat and biotic stress induced BVOC emissions in Pseudotsuga menziesii, Atmos. Environ., 45, 36553662, 2011.

Kännaste, A., Vongvanich, N., and Borg-Karlson, A.-K.: Infestation by a Nalepella species induces emissions of $\alpha$ - and $\beta$-farnesenes, (-)-linalool and aromatic compounds in Norway spruce clones of different susceptibility to the large pine weevil, Arthropod-Plant. Inte., 2, 31-41, 2008.

Knight, D. H., Yavitt, J. B., and Joyce, G. D.: Water and nitrogen outflow from lodgepole pine forest after two levels of tree mortality, Forest Ecol. Manag., 46, 215-225, 1991.

Knowles, P. and Grant, M. C.: Age and size structure analyses of Engelmann spruce, ponderosa pine, lodgepole pine, and limber pine in Colorado, Ecology, 64, 1-9, 1983.

Kurz, W. A., Dymond, C. C., Stinson, G., Rampley, G. J., Neilson, E. T., Carroll, A. L., Ebata, T., and Safranyik, L.: Mountain pine beetle and forest carbon feedback to climate change, Nature, 452, 987-990, 2008.

Lusebrink, I., Evenden, M. L., Blanchet, F. G., Cooke, J. E. K., and Erbilgin, N.: Effect of water stress and fungal inoculation on monoterpene emission from an historical and a new pine host of the mountain pine beetle, J. Chem. Ecol., 37, 1013-1026, 2011.

Mitton, J. B. and Ferrenberg, S. M.: Mountain pine beetle develops an unprecedented summer generation in response to climate warming, Am. Nat., 179, 163-171, doi:10.1086/665007, 2012.

Ng, N. L., Kroll, J. H., Keywood, M. D., Bahreini, R., Varutbangkul,V., Flagan, R. C., Seinfeld, J. H., Lee, A., and Goldstein, A. H.: Contribution of first- versus second-generation products to secondary organic aerosols formed in the oxidation of biogenic hydrocarbons, Environ. Sci. Technol., 40, 2283-2297, 2006.

Ormeño, E., Fernandez, C., Bousquet-Mélou, A., Greff, S., Morin, E., Robles, C., Vila, B., and Bonin, G.: Monoterpene and sesquiterpene emissions of three Mediterranean species through calcareous and siliceous soils in natural conditions, Atmos. Environ., 41, 629-639, 2007.

Ortega, J. and Helmig, D.: Approaches for quantifying reactive and low-volatility biogenic organic compound emissions by vegetation enclosure techniques - Part A, Chemosphere, 72, 343-364, 2008. 
Pendall, E., Ewers, B., Norton, U., Brooks, P., Massman, W. J., Barnard, H., Reed, D., Aston, T., and Frank, J.: Impacts of beetle-induced forest mortality on carbon, water and nutrient cycling in the Rocky Mountains, FluxLetter (The Newsletter of FLUXNET), 3, 17-21, 2010.

Pettersson, E. M.: Volatiles from potential hosts of Rhopalicus tutela a bark beetle parasitoid, J. Chem. Ecol., 27, 2219-2231, 2001.

Powell, E. N. and Raffa, K. F.: Fire injury reduces inducible defences of lodgepole pine against mountain pine beetle, J. Chem. Ecol., 37, 1184-1192, 2011.

Pugh, E. and Small, E.: The impact of pine beetle infestation on snow accumulation and melt in the headwaters of the Colorado River, Ecohydrology, 5, 467-477, doi:10.1002/eco.239, 2012.

Raffa, K. F., Aukema, B. H., Bentz, B. J., Carroll, A. L., Hicke, J. A., Turner, M. G., and Romme, W. H.: Cross-scale drivers of natural disturbances prone to anthropogenic amplification: The dynamics of bark beetle eruptions, Bioscience, 58, 501-517, 2008.

Robbins, J.: What's killing the great forests of the American west? Yale Environment 360, Report, Yale School of Forestry and Environmental Studies, available at: http://e360.yale.edu/content/ feature.msp?id $=\{2252\}$ (last access: 4 May 2012), 2010.

Safranyik, L., Carroll, A. L., Régnière, J., Langor, D. W., Riel, W. G., Shore, T. L., Peter, B., Cooke, B. J., Nealis, V. G., and Taylor, S. W.: Potential for range expansion of mountain pine beetle into the boreal forest of North America, Can. Entomol., 142, 415$442,2010$.

Schoettle, A. W.: The interaction between leaf longevity and shoot growth and foliar biomass per shoot in Pinus contorta at two elevations, Tree Physiol., 7, 209-214, 1990.

Seybold, S. J., Huber, D. P. W., Lee, J. C., Graves, A. D., and Bohlmann, J.: Pine monoterpenes and pine bark beetles: A marriage of convenience for defense and chemical communication, Phytochem. Rev., 5, 143-178. 2006.
Sibold, J. S., Veblen, T. T., and González, M. E.: Spatial and temporal variation in historic fire regimes in subalpine forests across the Colorado Front Range in Rocky Mountain National Park, Colorado, USA, J. Biogeogr., 33, 631-647, doi:10.1111/j.13652699.2005.01404.x, 2006.

Sibold, J. S., Veblen, T. T., Chipko, K., Lawson, L., Mathis, E., and Scott, J.: Influences of secondary disturbances on lodgepole pine stand development in Rocky Mountain National Park, Ecol. Appl., 17, 1638-1655, 2007.

Steiner, A. L., Tonse, S., Cohen, R. C., Goldstein, A. H., and Harley, R. A.: Biogenic 2-methyl-3-buten-2-ol increases regional ozone and HOx sources, Geophy. Res. Lett., 34, L15806, doi:10.1029/2007GL030802, 2007.

United States Department of Agriculture (USDA) Forest Service, Review of the Forest Service response: The bark beetle outbreak in northern Colorado and southern Wyoming, available at: http://www.fs.fed.us/rmrs/docs/home/bark-beetle. pdf (last access: 4 May 2012), 2011.

Veblen, T. T. and Donnegan, J. A.: Historical range of variability for forest vegetation of the national forests of the Colorado front range, Final Report to the USDA Forest Service, University of Colorado, Boulder, Colorado, pp. 151, 2005.

Wiedinmyer, C., Barlage, M. J., Tewari, M., and Chen, F.: Meteorological impacts of forest mortality due to insect infestation in Colorado, Earth Interact.,16, 1-11, doi:10.1175/2011EI419.1, 2012.

Zavarin, E., Critchfield, W. B., and Snajberk, K.: Turpentine composition of Pinus contorta $x$ Pinus banksiana hybrids and hybrid derivatives, Can. J. Botany, 47, 1443-1453, 1969. 